\title{
LEARNING-BY-DOING VS. ON-THE-JOB TRAINING: USING VARIATION INDUCED BY THE EITC TO DISTINGUISH BETWEEN MODELS OF SKILL FORMATION
}

\author{
James J. Heckman \\ Lance Lochner \\ Ricardo Cossa
}

Working Paper 9083

http://www.nber.org/papers/w9083

\author{
NATIONAL BUREAU OF ECONOMIC RESEARCH \\ 1050 Massachusetts Avenue \\ Cambridge, MA 02138 \\ July 2002
}

This research was sponsored by NSF-97-09-873 and NSF-SES-0079195 and a grant from the American Bar Foundation. This paper was presented at a conference on wage subsidies sponsored by the Russell Sage Foundation in New York, December, 1997, IRP conference at the University of Wisconsin, June, 1998, at the Western Economics Association Meeting, July, 1998, at the University of Rochester, November 1998, and at a Public Sector Workshop at the University of Chicago, May 1999. We thank Alejandra Cox Edwards, Nada Eissa, Larry Summers, Edmund Phelps and especially Casey Mulligan and Yona Rubenstein for comments on this paper. The views expressed herein are those of the authors and not necessarily those of the National Bureau of Economic Research.

(C) 2002 by James J. Heckman, Lance Lochner and Ricardo Cossa. All rights reserved. Short sections of text, not to exceed two paragraphs, may be quoted without explicit permission provided that full credit, including (C) notice, is given to the source. 
Learning-By-Doing Vs. On-the-Job Training: Using Variation Induced by the EITC to Distinguish Between Models of Skill Formation

James J. Heckman, Lance Lochner and Ricardo Cossa

NBER Working Paper No. 9083

July 2002

JEL No. H24, J24, J31

\begin{abstract}
This paper investigates the impact of wage subsidies on skill formulation. We analyze two prototypical models of skill formation: (a) a learning-by-doing model and (b) an on-the-job training model. We develop conditions on the pricing of jobs under which the two models are equivalent. In general they are different and have different implications of wage subsidies on skill formation. On-the-job training models predict that wage subsidies reduce skill formation. Learning-by-doing models predict the opposite. The provisional evidence favors the learning-by-doing model. We apply our estimates to investigate the impact of the EITC on skill formation. We estimate that the EITC reduced the long term wages of participants with low levels of education.
\end{abstract}

James Heckman

Department of Economics

University of Chicago

1126 East 59th Street

Chicago, IL 60637

and NBER

jjh@uchicago.edu
Lance Lochner

Department of Economics

University of Rochester

Rochester, NY 14627

and NBER

lance@troi.cc.rochester.edu
Ricardo Cossa

University of Chicago

140 South Dearborn Street

Suite \#1500

Chicago, IL 60603

cossa@chipar.com 


\section{Introduction}

Recent calls for wage subsidies have emphasized their value for attaching low skill persons to the workplace, attracting them away from lives of idleness or crime (Phelps, 1997; Heckman, Lochner, Smith, and Taber, 1997; and Lochner, 1998). Previous empirical research on wage subsidies has focused exclusively on their effects on employment and labor supply. This paper examines the impact of wage subsidies on skill formation.

By promoting work among those who would not otherwise work, wage subsidies create incentives for workers to invest in skills that are useful in the workplace. The skill formation effects of wage subsidies on persons who would work without the subsidy are more subtle. If skills are acquired as a by-product of work (learning-by-doing), wage subsidies will encourage skill acquisition to the extent that workers increase their labor supply in response to the subsidy. However, if learning is rivalrous with working, as in Becker (1964) or Ben Porath (1967), wage subsidies can discourage investment in skills.

There are even more subtle effects of wage subsidies on skill formation arising from the nonlinearity in the return to work created by many proposed schemes. These nonlinearities arise from the targeted nature of most programs. Specifically, consider the Earned Income Tax Credit (EITC), which supplements annual labor earnings for those who work as shown in Figure $1 .^{1}$ (For analytical simplicity, we abstract from all other tax and transfer programs implicitly assuming that they generate proportional schedules that preserve Figure 1 as a key feature of the budget set facing workers. Whether or not this is true is an open empirical question.) In the first region of Figure 1, $[0, a)$, the hourly wage is subsidized. In the second region, $[a, b)$, the hourly wage is the pre-subsidy wage, but the worker's total income is increased by the amount of the annual subsidy, $S_{b}$. In the third region, $[b, c)$, the subsidy is phased out and the effective hourly wage is below the pre-subsidy wage level, because each hour worked eliminates part of the subsidy. When earnings are sufficiently high, at or above $c$, the effective wage again equals the pre-subsidy wage. In this paper, we consider the effect of this subsidy on skill formation.

In the standard Becker - Ben Porath economic model of skill formation, the major cost of skill investment is foregone earnings. Assume, for simplicity, that these are the only costs and ignore foregone leisure. Time is devoted either to work or investment and people seek to maximize the present value of their earnings. (We temporarily abstract from the labor-leisure decision in order to focus on the main impact of the program on skill investment without worrying about wealth effects on labor supply.)

If skills do not depreciate, wages always rise (or remain constant) over the life cycle as skill investments are made. For a person starting life on the first segment of the EITC schedule, the opportunity cost of time investing in skill is raised compared to what it would be in the absence

\footnotetext{
${ }^{1}$ Strictly speaking, the EITC subsidizes wage earnings rather than wage rates. For a given pre-subsidy wage, the EITC alters the post-subsidy wage received for each hour worked and is effectively a wage subsidy.
} 
of the program. If the investment produces sufficient earnings growth so that persons eventually leave the first segment as their skills are enhanced, the effect of the subsidy is to reduce skill formation, because the opportunity cost of time spent investing is increased during the years when investment is made but the wage payment per hour of work is not increased during the payoff years. Only if a person stays on the first segment throughout his working lifetime will the effect of the subsidy be neutral on skill formation. In this case, marginal returns and costs rise in the same proportion and there is no effect on skill investment.

For a person who starts life on the flat segment of the subsidy schedule, the effects of the subsidy on investment are ambiguous. First, if a person has annual earnings that never leave the flat segment, there is no effect of the subsidy on skill formation, since there is no marginal effect of the program on either returns or costs. ${ }^{2}$ Second, if earnings rise so that the person spends part of his or her career on the declining segment, skill formation is retarded, because the payoff to investment in human capital is reduced as the subsidy is withdrawn. If a person jumps from the flat segment to a post-program earnings level above $c$, there again would be no effect of the program on skill formation, although the continuous nature of the skill formation process makes this case an empirically unlikely one.

Finally, consider a person who begins life with initial earnings in the phase-out segment. In this case, the implicit tax on earnings makes investment less costly compared to a no-program world, since earnings foregone are reduced by the subsidy. If investment eventually causes the person to leave the third segment, the tax on earnings is eventually removed and, hence, the relative payoff to investment is increased by the subsidy. This case promotes skill formation.

The overall effect of the program on the skill formation of workers affected by the program is ambiguous even in this simple model. It depends on where workers' earnings place them in the schedule and can only be determined by an empirical analysis. Adding the labor-leisure choice further complicates matters. The wealth effects of the subsidy serve to reduce labor supply and, hence, the incentive to acquire skills. For workers spending their entire careers on the plateau or in the phase-out region, wealth effects created by the EITC cause labor supply and investment to decline. Wage effects are ambiguous, depending on the relative strengths of income and substitution effects. When substitution effects dominate, the EITC encourages skill investment for individuals who spend their entire careers in the phase-in region or for those who move from the phase-out region off the schedule. Finally, the EITC may draw people into the workplace. This will increase their hours of work and will increase their incentive to invest in work-related skills.

Persons may also be drawn into the workforce by the EITC when skills are acquired through work experience rather than through a separate learning activity as in the Becker - Ben Porath model. In the conventional learning-by-doing model, investment time and work are the same, and

\footnotetext{
${ }^{2}$ Recall that we assume that there are no wealth effects
} 
the activity of investment is not rivalrous with work. In this framework, the effects of the EITC on skills accumulated through learning-by-doing are much different. For those who would work even in the program's absence, skill accumulation depends only on labor supply. So, for workers induced to work more hours, the EITC raises skills. Those induced to work less by the program accumulate fewer skills. The EITC only raises hours worked among workers whose earnings lie in the phase-in region of the schedule, assuming substitution effects dominate income effects in determining labor supply. For all other workers, the EITC reduces hours worked and, therefore, skills acquired through learning-by-doing. The contrast between the effects of wage subsidies on skill formation in a learning-by-doing model and in a Becker - Ben Porath model is a major finding of this paper.

In order to clarify the essential features of the program, we initially simplify the analysis. In Section 2, we use a two period model of skill formation to analyze the effects of age-specific proportional wage subsidies or wage taxes on skill acquisition for several types of subsidy programs using the two competing models of skill formation. At any age, we assume that tax or subsidy rates are the same irrespective of earnings levels. Thus, we initially abstract from the endogenously determined tax/subsidy rates of the EITC to avoid non-concavity of the criterion and nonuniqueness in investment.

We establish that the two main models of skill formation widely used in the literature, the Becker - Ben Porath on-the-job training (OJT) model and a learning-by-doing (LBD) model, have different implications for the effect of wage subsidies on skill formation. When the conventional LBD model is carefully examined, it contains an apparent "free lunch" feature - persons who work also acquire skill. The more they work, the more skills they acquire, so no earnings are foregone. Foregone leisure is the sole cost of investment in this model. When a market for jobs with different learning content is introduced following Rosen (1972), earnings foregone are added as a cost of acquiring skills in a learning-by-doing model and the two models become much more similar. In a very special case, which we establish below, the two models are equivalent if leisure is added to the Becker - Ben Porath framework and if learning-by-doing opportunities are priced appropriately.

In Section 3, we discuss specific features of the EITC program. We go beyond the simple analysis of age-specific wage subsidies to consider the actual wage subsidies implicit in the EITC program, which depend on the level of earnings. We discuss the resulting non-differentiability and non-concavity of the criterion function as well as the need to account for a multiplicity of local optima in estimating the impact of the EITC program and simulating its impact.

We present an analysis of the distribution of female workers with low education over the four segments of Figure 1. The least educated typically begin their careers in the phase-in region, $[0, a)$, and move to either the plateau region, $[a, b)$, or phase-out region, $[b, c)$. Thus, investment is initially discouraged in the OJT framework, while work (and learning) are encouraged in the 
LBD framework. Wealth effects of the EITC typically reduce skill acquisition in both models of skill formation for women receiving substantial credit amounts.

Section 4 extends the analysis of Section 3 to a multi-period setting. The intuition developed in the simple two period models applies more generally. Section 5 presents estimates of two canonical models of skill formation using CPS data on wages and hours worked for women with low levels of education.

Section 6 uses those estimates to explore the impacts of the EITC program on earnings and wage growth in the two different models of skill formation. Both models produce similar estimates of EITC-induced entry into the workforce and its associated human capital accumulation. The models differ greatly in their prediction of the quantitative impact of the EITC program on the wage growth of those who would work even in the absence of the program. Qualitatively, the models agree. Both predict declines in potential skill levels among the women we study. But the predicted declines are quantitatively greater in the OJT model than in the LBD model. The LBD model predicts substantially larger negative impacts of the EITC on hours worked. As a result, it also predicts larger declines in earnings than the OJT model. If the entry effects of the EITC are small, the reductions in average earnings among all uneducated women can be as large as $18 \%$ of the average skill level supplied to the market. While the aggregate effects of the EITC on skills are similar in the two models, the predicted impacts on specific groups of workers are often quite different depending on which region of the schedule a worker spends most of her time. ${ }^{3}$ Average measures of the impact of the EITC on skills mask considerable heterogeneity in individual responses. These findings highlight the importance of determining the appropriate model of skill formation in assessing the impact of the EITC program on the skills and earnings of workers.

Section 7 briefly discusses other empirical evidence about the process of skill formation, and Section 8 summarizes and concludes.

\section{Models of Wage Subsidies and Skill Formation}

This section analyzes several two period models of skill accumulation to investigate the effect of period-specific proportional wage subsidies on skill formation. The EITC is not a periodspecific proportional wage subsidy. But the intuition obtained from an analysis of the simple period-specific proportional subsidy and tax case carries over to the more general EITC structure. We consider both income maximizing models and models with labor supply assuming perfect credit markets. ${ }^{4}$ Throughout this paper, we ignore the practically important issues of fraud and

\footnotetext{
${ }^{3}$ Even greater heterogeneity is observed when the impacts of the EITC on male earnings and more educated workers are considered. See Heckman, Lochner and Cossa (1999).

${ }^{4}$ In Heckman, Lochner and Cossa (1999) we consider versions of our labor supply models with borrowing constraints. Analytically, the quantitative features are quite similar to those presented here; even the quantitative results from our simulations in Section 6 do not change much when borrowing constraints are imposed.
} 
enforcement in the administration of wage subsidy programs that are discussed by Phelps (1997).

Central to our investigation is the specification of the skill formation process. The conventional Becker - Ben Porath model features earnings foregone as the main cost of skill formation. In this model, a wage subsidy in the first period of a two period model tends to divert workers away from investment and toward market work. On the other hand, second period wage subsidies encourage first period investment.

A model of learning-by-doing (as developed by Heckman, 1971, Weiss, 1972, Killingsworth, 1982, Shaw, 1989, and Altug and Miller, 1990 and 1998) produces completely different predictions. In this model, an hour of work at any job produces general skills that have the same value in all sectors of the economy. A wage subsidy that promotes work in the first period promotes skill formation. The cost of work and skill acquisition in this model is leisure foregone.

This second model of skill formation appears to have a free lunch aspect to it. People who work more earn more in that period and in the future. There is no tradeoff between skill formation and earnings from work as in the Becker - Ben Porath model. Yet, learning is not entirely free, since a tradeoff between leisure and acquiring skills through work still exists.

What produces the apparent free lunch is the implicit assumption that for any worker an hour of work in any job is equally effective in producing skill. If jobs differ in the rate at which an hour of work produces skill, a market for jobs arises that is usually ignored in analyses of learning-by-doing models. All current workers who plan to work in the future will cluster in jobs with the highest learning content unless those jobs command higher prices. Higher prices for jobs with more training content mean lower first period wages for such jobs if workers of the same skill level and tastes have choices among otherwise equal jobs with different training content. ${ }^{5}$ With the addition of heterogeneity in learning opportunities, and prices of those opportunities, a tradeoff between first period investment and earnings from work re-emerges.

\subsection{Specifications of Skill Formation Equations}

The most commonly used specification of the human capital accumulation process is due to Ben Porath (1967). Human capital in period $1, H_{1}$, is produced by time investment $I$. (We assume there is no depreciation, so human capital is non-decreasing.) Thus, we write

$$
H_{1}-H_{0}=F(I)
$$

with $F^{\prime}>0, F^{\prime \prime}<0,0 \leq I \leq 1$, where $I$ is the proportion of time spent investing, and $H_{0}$ is the initial stock of human capital.

Assuming a perfect capital market with interest rate $r$ and an efficiency units model of labor services with price $R$ per efficiency unit of human capital, and period 0 and 1 tax/subsidy rates

\footnotetext{
${ }^{5}$ Rosen (1972) introduced the notion of a market for jobs with different training/learning content.
} 
of $\tau_{0}$ and $\tau_{1}$, respectively, agents choose $I$ to maximize

$$
\left(1+\tau_{0}\right) R H_{0}(1-I)+\frac{\left(1+\tau_{1}\right) R}{1+r} H_{1}
$$

subject to (1). Investment is rivalrous with earnings. This formulation recognizes that there will be no investment in the second (and final) period of life. ${ }^{6}$

Optimality requires that

$$
\left(1+\tau_{0}\right) R H_{0} \leq \frac{\left(1+\tau_{1}\right) R}{1+r} F^{\prime}(I)
$$

Changes in $R$ do not affect skill investment. At an interior $(0<I<1)$, increases in $r$ and $H_{0}$ decrease investment. The higher the first period opportunity wage or the lower the discounted return from investment, the less time is spent investing. ${ }^{7}$

A common wage subsidy or tax across periods $\left(\tau_{0}=\tau_{1}\right)$ clearly does not affect investment. Both the marginal returns and marginal costs are affected equally. However, if $\tau_{0}>\tau_{1}$, investment is reduced compared to the case where $\tau_{0}=\tau_{1}$; if $\tau_{0}<\tau_{1}$, then investment is increased. We return to this model and analyze it more thoroughly after we develop a comparison model of learning-by-doing.

In the LBD model, skills are produced by work. Let $L_{t}$ be leisure in period $t$. There is no investment time, so hours of work in period $t$ are given by $1-L_{t}$. In this scheme,

$$
H_{1}-H_{0}=\varphi\left(1-L_{0}\right)
$$

with $\varphi^{\prime}>0, \varphi^{\prime \prime}<0$. In principle, work in the second period also produces human capital, but that output is not valued since there is no third period. The cost of work and acquiring new skills is leisure foregone. To introduce such costs, it is necessary to introduce a utility function that values leisure. Then, individuals choose consumption and leisure to

$$
\operatorname{Max} U\left(C_{0}, L_{0}\right)+\frac{1}{1+\rho} U\left(C_{1}, L_{1}\right)
$$

(where $U$ is strictly concave in its arguments and $\rho$ is a time discount factor) subject to the lifetime budget constraint

$$
R H_{0}\left[1-L_{0}\right]\left(1+\tau_{0}\right)+\frac{R}{1+r} H_{1}\left[1-L_{1}\right]\left(1+\tau_{1}\right)+A_{0}=C_{0}+\frac{C_{1}}{1+r}
$$

and (1) where $A_{0}$ represents initial assets. Throughout this paper, we assume that goods and leisure are normal. Let $\lambda$ denote the LaGrange multiplier associated with (3). Assuming an interior solution, we obtain the following first order conditions:

$$
\begin{aligned}
& U_{1}\left(C_{0}, L_{0}\right)=\lambda \\
& U_{1}\left(C_{1}, L_{1}\right)=\lambda\left(\frac{1+\rho}{1+r}\right) \\
& U_{2}\left(C_{0}, L_{0}\right)=\lambda R\left(H_{0}\left(1+\tau_{0}\right)+\frac{\varphi^{\prime}\left(1-L_{0}\right)\left[1-L_{1}\right]\left(1+\tau_{1}\right)}{1+r}\right)
\end{aligned}
$$

\footnotetext{
${ }^{6}$ In this paper, we only consider the individual's problem, ignoring the general equilibrium effects of policy on factor prices.

${ }^{7}$ At the $I=1$ boundary, we obtain the stated results as "tendencies" i.e. predicted increases in investment become predicted non-decreases.
} 


$$
U_{2}\left(C_{1}, L_{1}\right)=\lambda\left(\frac{1+\rho}{1+r}\right) R\left(H_{0}+\varphi\left(1-L_{0}\right)\right)\left(1+\tau_{1}\right) .
$$

The price of time in the first period includes potential earnings $\left(R H_{0}\left(1+\tau_{0}\right)\right)$ plus the effect of an extra unit of work on discounted future earnings. As first noted by Heckman (1971), even when $\rho=r$, it is possible that wages grow between periods 0 and 1 , but labor supply remains the same. This occurs if the total opportunity cost of leisure $\left(R H_{0}\left(1+\tau_{0}\right)+\frac{R \varphi^{\prime}\left(1-L_{0}\right)\left[1-L_{1}\right]\left(1+\tau_{1}\right)}{1+r}\right)$ in period 0 equals the realized wage in period $1\left(R H_{0}+R \varphi\left(1-L_{0}\right)\left(1+\tau_{1}\right)\right)$.

In this model, an increase in $R$ produces income and substitution effects. Compensating to eliminate income effects (holding $\lambda$ constant), an increase in $R$ promotes skill formation and labor supply. There is no tradeoff between investment and work, because work is investment. If wages are subsidized $\left(\tau_{0}>0\right)$ in period 0 and taxed $\left(\tau_{1}<0\right)$ in period 1 , the effects on skill formation are ambiguous: the first period wage, $R H_{0}\left(1+\tau_{0}\right)$, is increased but the future return, $\frac{R \varphi^{\prime}\left(1-L_{0}\right)\left[1-L_{1}\right]}{1+r}\left(1+\tau_{1}\right)$, is diminished.

In contrast to the model of skill investment previously analyzed, a compensated wage subsidy in period zero that is changed to a wage tax in period one has ambiguous effects. It may increase skills if the positive effects on current returns more than offset the negative effects on future returns. Similarly, a compensated wage tax applied in period zero followed by a wage subsidy in period one also has ambiguous effects on skills. The resulting increase in the return on future work may promote work (and, hence, learning) in the initial period. If $\tau_{1}=0$, a wage subsidy in period $0\left(\tau_{0}>0\right)$ promotes skill formation, while a wage tax $\left(\tau_{0}<0\right)$ lowers skills - exactly the opposite of what is predicted in the Becker - Ben Porath investment framework.

\subsection{Reconciling the Two Models of Skill Formation}

The two models just considered have different predictions about the effects of simple tax and subsidy schemes on skill formation. What is the source of this difference? We now show that adding leisure to the first model does not change the qualitative predictions derived from it, provided that we compensate for income effects and that solutions are interior. Allowing different jobs to have different training content and pricing out the training moves the two models together.

To augment the first model, the utility function described by (2) is maximized with respect to consumption, leisure, and investment subject to the lifetime budget constraint:

$$
R H_{0}\left[1-I-L_{0}\right]\left(1+\tau_{0}\right)+\frac{R}{1+r}\left[F(I)+H_{0}\right]\left[1-L_{1}\right]\left(1+\tau_{1}\right)+A_{0}=C_{0}+\frac{C_{1}}{1+r} .
$$

(This expression incorporates the observation that there is no investment, $I$, in the final period.) The interior first order conditions for leisure and investment become

$$
\begin{aligned}
& U_{2}\left(C_{0}, L_{0}\right)=\lambda R H_{0}\left(1+\tau_{0}\right) \\
& U_{2}\left(C_{1}, L_{1}\right)=\lambda R\left[H_{0}+F(I)\right]\left(\frac{1+\rho}{1+r}\right)\left(1+\tau_{1}\right) \\
& \frac{R}{1+r} F^{\prime}(I)\left[1-L_{1}\right]\left(1+\tau_{1}\right)=R H_{0}\left(1+\tau_{0}\right) .
\end{aligned}
$$


In this extended Becker - Ben Porath OJT model, changes in $R$ are no longer neutral. Holding wealth effects constant, an increase in $R$ increases skill formation by encouraging labor supply in period 1. The qualitative effects of changes in taxes and subsidies in periods 0 and 1 are the same as in the income maximizing version of this model. If $\tau_{0}<0$ and $\tau_{1}>0$, skill accumulation is fostered compared to the case where $\tau_{0}=\tau_{1}=0$. If $\tau_{0}>0$ and $\tau_{1}<0$, skill accumulation is dampened. Adding leisure but compensating for wealth effects, we obtain the same predictions about the impact of period-specific wage subsidies on investment as those produced in the original Becker - Ben Porath model. The crucial economic difference between the OJT and LBD models of skill formation is not that one model excludes leisure while the other includes it. Rather, the major source of the difference derives from the fact that investment and labor supply compete for the agent's time in the OJT model, while they do not in the LBD model.

Now consider another case where firms differ in the rate at which workers learn from an hour of work. All workers who plan to work in period 1 would flock to the firms offering the highest total earnings package (inclusive of future earnings). If firms pay the same spot wage, $R$, for $H_{0}$, the firm with the higher learning potential would attract all the workers if it did not charge for its learning opportunities. Only workers who did not plan to work in period 1 would ignore the training potential of a prospective job. Those who plan to work a lot would value it highly.

To investigate this model more systematically, let $\theta$ index the investment content of a job, so we write the learning-by-doing function as $\varphi\left(1-L_{0} ; \theta\right)$. Assume

$$
\frac{\partial^{2} \varphi}{\partial \theta \partial\left(1-L_{0}\right)}>0
$$

so opportunities with higher $\theta$ produce greater learning-by-doing per hour of work. Assume further that $\varphi(0 ; \theta)=0$, for all $\theta$, so that a person must work in order to harvest the benefit of $\theta$. For the same wage, $R H_{0}$, young workers would prefer to work in firms with higher $\theta$. Only persons who choose not to work in the future are unconcerned about the $\theta$ content of their job. Implicit in the learning-by-doing specifications used in the literature is the assumption that all firms provide the same learning opportunities - i.e. $\theta$ is identical across firms.

If it is not, and if there is a distribution of $\theta$ across firms, say with an upper limit $\bar{\theta}$ and a lower limit $\underline{\theta}$, and if, for whatever reason, there are two or more $\theta$-types of firms in the market at any time, then a market price for training, $P(\theta)$, will emerge. The exact specification of the pricing function critically affects the analysis and depends on both supply and demand factors for labor and learning. In this revised LBD model, the agent's problem is to choose $\theta$ along with $C_{0}, C_{1}, L_{0}$, and $L_{1}$ subject to the revised budget constraint. Consider two firms that differ in their training effectiveness. Firm 1 offers less learning, so $\theta_{1}<\theta_{2}$. For the same hours of work in period 0 , an hour of work at firm 2 produces greater earnings in period 1 . The more hours spent working in period 1, the greater the gain from working at firm 2 in period 0 . If there were an unlimited supply of training opportunities at $\theta=\bar{\theta}$, all young workers would congregate at firms 
with such opportunities if they plan to work in the second period. If the supply of training jobs is limited for some reason, workers will sort to firms with different $\theta$-types. A market for training options will emerge. Ceteris paribus, workers who will work more in the second period will place greater value on high $\theta$ jobs, and will be willing to pay more for them.

For analytical simplicity, assume a continuum of $\theta$-type firms co-exist in the market where $\theta \in[\underline{\theta}, \bar{\theta}]$ Young workers who do not plan to work in period 1 will sort into low $\theta$ firms. So will old workers. We assume that the price for a job of type $\theta$ exists and the pricing function $P(\theta)$ is differentiable in $\theta .^{8}$ In this specification, we think of the firm as providing a learning environment common for all workers irrespective of the hours they work. Persons who work more will derive more learning from their jobs. A fixed charge $P(\theta)$ is paid by all workers in the firm. Assuming that firms use $H$ in production and that only efficiency units matter in producing final output, the gross payment to human capital is $R H$ for a person with human capital bundle $H$.

The pre-subsidy period 0 earnings for a person who chooses a job $\theta$ and has human capital $H_{0}$ is

$$
W\left(H_{0}, \theta\right)=R H_{0}\left(1-L_{0}\right)-P(\theta)
$$

The pre-subsidy hourly wage rate is

$$
w\left(H_{0}, \theta\right)=W\left(H_{0}, \theta\right) /\left(1-L_{0}\right)
$$

The pre-subsidy hourly wage understates the potential wage rate, $R H_{0}$, as long as $P(\theta)>0$. The understatement is greater the greater the learning content of the job. ${ }^{9}$

The budget constraint for the extended learning-by-doing model is

$$
\left[R H_{0}\left[1-L_{0}\right]-P(\theta)\right]\left(1+\tau_{0}\right)+\frac{R H_{1}\left[1-L_{1}\right]\left(1+\tau_{1}\right)}{1+r}+A_{0}=C_{0}+\frac{C_{1}}{1+r}
$$

and the revised skill accumulation equation is

$\left(1^{\prime}\right) \quad H_{1}-H_{0}=\varphi\left(1-L_{0} ; \theta\right)$.

With obvious notational changes to reflect the introduction of $\theta$, the first order conditions (4) and (5) are the same. The new first order condition arising from the choice of $\theta$ is

$$
\left(1+\tau_{0}\right) P^{\prime}(\theta)=\left(1+\tau_{1}\right)\left(\frac{R}{1+r}\right)\left[1-L_{1}\right] \frac{\partial \varphi\left(1-L_{0} ; \theta\right)}{\partial \theta} \cdot{ }^{10}
$$

\footnotetext{
${ }^{8}$ Rosen (1972) introduced the notion of a market for jobs with different learning content. He reinterprets the Ben Porath model to let $I$ play the role of the index $\theta$ in our notation. Different firms may offer jobs with different investment/learning content $I$, and firms producing more learning for workers produce less output of the consumption good. This generates an implicit market whereby firms charge workers an amount RHI for their learning. It also produces mobility across jobs as workers reduce $I$ over the life cycle. Rosen does not consider the learning-by-doing model analyzed in this paper, in which hours of work at a firm produce skill.

${ }^{9}$ This has substantial implications for econometric estimates of learning-by-doing models as estimated in Altug and Miller $(1990,1998)$. They implicitly assume that all firms offer the same training opportunities, and they are free. If training is costly, they understate the first period-wage, and the understatement is greater for firms with workers making more investment.

${ }^{10}$ To guarantee an interior solution for $\theta$, it is sufficient that $P^{\prime \prime}(\theta)>0$ and $\frac{\partial^{2} \varphi}{\partial \theta^{2}}<0$. More generally we just require that standard second order conditions hold.
} 
This equation makes clear that individuals who intend to work more in period 1 (e.g. if they have high skill levels or few assets) will sort into high $\theta$ jobs. In the second and final period, workers will cash out their investment and choose jobs with low training content.

In this amended learning-by-doing model, a compensated wage subsidy in period zero $\left(\tau_{0}>0\right)$ raises the cost of $\theta$ and causes agents to reduce the learning content of their work compared to the non-subsidized case $\left(\tau_{0}=0\right)$. The net effect on skill formation is ambiguous. Labor supply $\left(1-L_{0}\right)$ increases and $\theta$ decreases. Thus,

$$
\begin{aligned}
\left.\frac{\partial\left(H_{1}-H_{0}\right)}{\partial \tau_{0}}\right|_{\text {utility constant }}= & \left.\varphi_{1} \frac{\partial\left(1-L_{0}\right)}{\partial \tau_{0}}\right|_{\text {utility constant }} \\
& +\left.\varphi_{2} \frac{\partial \theta}{\partial \tau_{0}}\right|_{\text {utility constant }}
\end{aligned}
$$

The first term on the right hand side is positive, and the second term is negative, making the overall impact of the subsidy on skill formation ambiguous. A wage subsidy in the second period $\left(\tau_{1}>0\right)$ promotes investment.

If there are implicit prices for jobs with different training content, then a period 0 wage subsidy in a LBD model may retard skill formation, just as it does in a Becker - Ben Porath OJT model. In general, the extended LBD model considered here produces two offsetting effects. Compensating for income effects, a higher wage subsidy will induce more hours of work and will produce more skills. At the same time, subsidized agents shift to lower $\theta$ jobs so the investment content of learning is diminished. The net effect on skill formation is ambiguous. Adding back income effects tends to reduce incentives to acquire skills.

Notice the similarity in the first order condition for $\theta$, equation (8), and the first order condition for investment, $I$, in the Becker - Ben Porath model, equation (7). Conditions governing consumption are identical. The greatest difference between the models arises in the first order conditions for leisure. (Compare the conditions in (5) with those of (6)). If learning opportunities in a firm can be tailored to the individual worker and it is possible to appropriately price out each hour of learning for a fixed $\theta$, then the LBD model and the Becker - Ben Porath OJT model are analytically equivalent. However, this requires that firms be able to price $\theta$ differently for persons who work different hours in periods 0 and 1 . The simple pricing scheme $P(\theta)$ is not enough.

To see this, consider a more general pricing scheme for learning opportunities, $\theta$ :

$$
P\left(\theta, 1-L_{0}\right)=f(\theta)+\omega(\theta)\left[1-L_{0}\right]
$$

where $f(\theta)$ is a fixed charge for training opportunity $\theta$ and $\omega(\theta)$ is the marginal cost of an hour of training in a firm with learning parameter $\theta$.

Replacing $P(\theta)$ with the more general $P\left(\theta, 1-L_{0}\right)$ yields the revised first order condition for first period leisure: 


$$
U_{2}\left(C_{0}, L_{0}\right)=\lambda\left(R H_{0}\left(1+\tau_{0}\right)-\omega(\theta)\left(1+\tau_{0}\right)+R \frac{\partial \varphi}{\partial\left(1-L_{0}\right)} \frac{\left[1-L_{1}\right]\left(1+\tau_{1}\right)}{1+r}\right) .
$$

The new first order condition for $\theta$ now becomes

$$
\left(1+\tau_{0}\right)\left(f^{\prime}(\theta)+\omega^{\prime}(\theta)\left[1-L_{0}\right]\right)=\left(1+\tau_{1}\right) \frac{R\left[1-L_{1}\right]}{1+r} \frac{\partial \varphi}{\partial \theta} .
$$

Under certain conditions, the OJT model and the extended LBD model are analytically equivalent. To establish this equivalence observe that $\theta$ in the LBD model plays a role similar to $I$ in the OJT model with leisure. The marginal cost of $\theta\left(\left(1+\tau_{0}\right) \frac{\partial P}{\partial \theta}\right)$ plays the role of the marginal cost of $I\left(R H_{0}\left(1+\tau_{0}\right)\right)$. $\frac{\partial \varphi}{\partial \theta}$ and $F^{\prime}(I)$ play comparable roles in terms of investment productivity. The price of leisure, $L_{0}$, is the same in both models, if the firm is able to set the marginal price of $\theta$ as

$$
\omega(\theta)=\frac{\partial \varphi}{\partial\left(1-L_{0}\right)} \frac{R\left[1-L_{1}\right]}{1+r}\left(\frac{1+\tau_{1}}{1+\tau_{0}}\right)
$$

If this condition is satisfied, the marginal price of $L_{0}$ in both models is $R H_{0}\left(1+\tau_{0}\right)$. Qualitative predictions about the effects of taxes and subsidies on human capital and wage growth are identical in both models when $\theta$ is priced in this fashion. They can be made quantitatively identical with a suitable choice of $F$ and $\varphi$ and the parameters of the model.

For this equivalence to arise, firms must be able to price discriminate based on the current and future number of hours a worker wants to work. That is, firms must be able to marginally charge workers based on the total return they receive from learning at their $\theta$ firm. The marginal relative return to providing additional $\theta$ (scaled by its price) must match the marginal relative return to investment in the Becker - Ben Porath model.

In equilibrium, the pricing scheme for $\theta$ will depend not only on the technology of learning, but it also depends on the supply of learning capabilities $(\theta)$ at existing firms. Recall that the prices for $\theta$ arise from a market equilibrium between buyers and sellers of labor and learning opportunities. From these conditions, a hedonic pricing scheme for work/learning will arise. We would not expect the fine price discrimination required to equate the two models to arise in general. Furthermore, it seems extremely unlikely that firms can accurately predict the amount of hours a worker plans to work in the future, even if it could perfectly price their learning/work package. Thus, the two models are quite distinct and require separate analysis.

\subsection{Employment and Skill Formation}

For all of the models of skill formation we have discussed, subsidies that promote work compared to non-employment will promote the acquisition of skills. In the LBD model, subsidies in any period encourage employment in all periods. Wage subsidies in the first period promote first period employment thereby generating new skills. Those new skills create additional incentives to work in the second period. On the other hand, second period wage subsidies that create employment in the second period also raise the return to work in the initial period. In the Becker 
- Ben Porath OJT model, only subsidies that generate employment in the second period promote skill formation, because they raise the value of investment in the initial period. However, first period wage subsidies actually discourage skill formation, since investment is rivalrous with work.

\subsection{Schooling}

Schooling is defined as the case where $I=1$ in the Becker - Ben Porath model. Wage subsidies during the schooling years divert persons away from investment (in schooling or job training) and toward work. However, wage subsidies during the post-schooling years raise the payoff to work and, hence, promote schooling earlier on.

The learning-by-doing model must be extended to accommodate schooling. If schooling is modeled as an activity that is rivalrous with work, we obtain the same predictions from this model as from a Becker - Ben Porath model: wage subsidies during the schooling years reduce schooling. However, the reductions in overall skill formation are partially offset by increases in skill acquired through work experience.

We now adapt this framework to analyze the EITC program.

\section{The EITC Program and its Recipients}

\subsection{A Description of the EITC Program}

Beginning in 1975, the EITC program has provided a subsidy (or tax credit) to low income workers. The amount of the subsidy depends on total labor income as well as the number of children living with (supported by) the worker. ${ }^{11}$ For wage income $W$, the EITC schedule (for any given amount of children) can be described as follows:

$$
S(W)=\left\{\begin{array}{lll}
S_{a} W & W<a & \text { "phase-in" } \\
S_{b} & a \leq W<b & \text { "plateau" } \\
S_{b}-S_{c}(W-b) & b \leq W<c & \text { "phase-out" } \\
0 & W \geq c &
\end{array}\right.
$$

where $S_{a}=S_{b} / a$ and $S_{c}=S_{b} /(c-b)$. Figure 1 graphs the EITC schedule as a function of pre-subsidy earnings. In terms of the notation of the last section, $S_{a}$ plays the role of $(1+\tau)$, $\tau>0$, for a person with wages $w=W /(1-L)$ provided $W<a ; S_{b}$ corresponds to $\tau=0$ with $A_{0}$ enhanced by $S_{b}$; and phase three corresponds to $S_{c}=1+\tau$ with $\tau<0$ and asset income adjusted by $S_{b}+S_{c} b$. In the case of the EITC, however, the subsidy level depends on earnings levels, which depend on individual work and investment choices. The EITC program generates nondifferentiable constraints with non-convex regions so that some care must be taken in analyzing it.

\footnotetext{
${ }^{11}$ The current law states that only children under nineteen (or under 24 if a full-time student) living in the taxpayer's household for more than half of the calendar year qualify.
} 
If agents are uncertain about the exact location of the budget set, and we account for the effects of all other programs on the effective tax subsidy schedule facing workers, the problem of non-convexity may diminish. In this paper we focus on the EITC program in isolation of other programs, assuming that persons know their nonconvex budget set.

Table 1 shows the EITC schedule for tax year 1994 as an example. Families with two or more children receive the greatest credit for any given income level, with a maximum credit of $\$ 2,528$. Families with one dependent child can receive up to $\$ 2,038$, while adults with no children can receive at most $\$ 306$. While the amount of the subsidy has risen substantially since the early eighties (with major expansions in 1986, 1990, and 1993), the basic structure has not changed. Only modest changes have taken place since 1994.

\subsection{The Qualifying Population}

Since nearly $1 / 4$ of all families with two or more children who qualify for the EITC are headed by a single mother and more than $1 / 3$ of qualifying families with one child (or no children) are single women (see Table 2), we focus our empirical analysis on women. Furthermore, the EITC aims to supplement the incomes of less educated women. As a result, more than half of qualifying women have no college experience. We, therefore, further concentrate our efforts on understanding the role of the EITC in decisions among women with a high school education or less. Using the 1994 March Current Population Survey (CPS), we study the distribution of women qualifying for the EITC by age, race, and educational background.

We divide family income into seven distinct regions, including the phase-in, plateau, and phase-out zones, as well as regions around the kinks at $a, b$, and $c{ }^{12}$ The values of $a, b$, and $c$ depend on the number of qualifying children and are based on the 1994 EITC schedule shown in Table 1.

Since it is necessary to identify qualifying children, we limit our sample of potential female recipients to heads of household. The EITC amount is based on family earnings, so we add spouse's earnings, if present, to those of the household head. (We do not model joint labor supply decisions.) Earnings include wage income, farm self-employment income, and business self-employment income. We also limit our sample to women ages 18-65. When determining the number of qualifying children for a household, we include all of the household head's natural or adopted children, grandchildren, step children, and foster children under 19 (or under 24 if the child is currently enrolled in school full-time).

Table 3 shows the distribution of working female high school dropouts with one or two children with respect to their position within the EITC schedule. Overall, about 35-43\% of them have earnings low enough to place them in the phase-in region of the schedule, while around $30 \%$ lie in the phase-out region. Among single mothers with less than a high school education, around

\footnotetext{
${ }^{12}$ See Table A-1 of the appendix for a more detailed description of the seven regions.
} 
$50 \%$ have earnings in the phase-in region. Disaggregating by age, approximately $50 \%$ of all young female high school dropouts with children have earnings in the phase-in region. That number drops about ten percentage points each ten years of age for women with one child, due to rising income profiles over the life cycle. The fraction of women with two or more children and earnings in the phase-in region only declines as they move from their twenties to their thirties. The fraction of working dropouts in the phase-out region moves in the opposite direction from the fraction in the phase-in region. The fraction of working dropouts with one or two children who earn more than the maximum cutoff for the EITC is quite small, ranging from 5-17\%. Single women with little schooling are almost twice as likely to have earnings in the phase-in region as are married women who are the heads of their households. Single mothers earning more than the maximum allowable amount are quite rare.

As seen in Table 4, a somewhat similar story can be told for high school graduates (without any college), except that their earnings distribution is shifted to the right. About $20 \%$ of graduate mothers with one child and $27 \%$ with two or more children - most of them under age 30 - have earnings in the phase-in region. By age 30, a large majority of graduates have earnings in the phase-out region or higher. By age 40, about $40 \%$ of female high school graduates with children have earnings too high to qualify for the EITC.

In summary, dropout mothers typically earn incomes placing them in the phase-in region of the EITC schedule, while mothers with a high school diploma are more likely to have earnings in the phase-out region (and beyond). We next turn to a discussion of those impacts on skill formation and hours worked modifying the simple models developed in Section 2 to accommodate specific features of the EITC program. We extend the models to a multiperiod setting in Section 4.

\subsection{Allowing For Endogenous Tax-Subsidy Rates}

First, consider the income-maximizing Ben Porath model. Tax rates are endogenous under the EITC, so the agent's problem becomes:

$$
\text { (9) } \begin{aligned}
& \max _{I} V=\left[R H_{0}(1-I)\left(1+S_{a}\right)\right] \cdot 1\left(R H_{0}(1-I)<a\right) \\
+ & {\left[R H_{0}(1-I)+S_{b}\right] \cdot 1\left(a \leq R H_{0}(1-I)<b\right) } \\
+ & {\left[R H_{0}(1-I)\left(1-S_{c}\right)+S_{b}+S_{c} b\right] \cdot 1\left(b \leq R H_{0}(1-I)<c\right) } \\
+ & {\left[R H_{0}(1-I)\right] \cdot 1\left(R H_{0}(1-I) \geq c\right)+\left[\frac{R H_{1}\left(1+S_{a}\right)}{1+r}\right] \cdot 1\left(R H_{1}<a\right) } \\
+ & {\left[\frac{R H_{1}+S_{b}}{1+r}\right] \cdot 1\left(a \leq R H_{1}<b\right)+\left[\frac{R H_{1}\left(1-S_{c}\right)+S_{b}+S_{c} b}{1+r}\right] \cdot 1\left(b \leq R H_{1}<c\right) } \\
+ & {\left[\frac{R H_{1}}{1+r}\right] \cdot 1\left(R H_{1} \geq c\right) }
\end{aligned}
$$

subject to the human capital production function, $F(I)$, where $1(A)=1$ if $A$ is true; $1(A)=0$ otherwise.

This ungainly expression captures the essential features of the EITC program. First, it induces a non-differentiable reward function, and second, it introduces a non-concavity to the problem. 
For payoff function $V$, we are not guaranteed that $V$ is everywhere concave, i.e. for $\bar{I}=\lambda I_{1}+$ $(1-\lambda) I_{2}$ and $0 \leq \lambda \leq 1$,

$$
V(\bar{I}) \geq \lambda V\left(I_{1}\right)+(1-\lambda) V\left(I_{2}\right)
$$

Appendix B formally demonstrates how non-concavity can arise for persons starting in the phaseout region. This potential nonconcavity leads to multiple local optima in some cases, and requires non-local methods for solving and estimating the model. (The problem becomes even more difficult when more periods are added to the model, as in Section 4.)

All of the other skill accumulation models are similarly plagued by this problem. In the Becker - Ben Porath model with leisure, the budget constraint has to be revised to account for the schedule in the following way:

$$
\text { (10) } \begin{aligned}
& A_{0}+\left[R H_{0}\left(1-I-L_{0}\right)\left(1+S_{a}\right)\right] \cdot 1\left(R H_{0}\left(1-I-L_{0}\right)<a\right) \\
+ & {\left[R H_{0}\left(1-I-L_{0}\right)+S_{b}\right] \cdot 1\left(a \leq R H_{0}\left(1-I-L_{0}\right)<b\right) } \\
+ & {\left[R H_{0}\left(1-I-L_{0}\right)\left(1+S_{c}\right)+S_{b}+S_{c} b\right] \cdot 1\left(b \leq R H_{0}\left(1-I-L_{0}\right)<c\right) } \\
+ & {\left[R H_{0}\left(1-I-L_{0}\right)\right] \cdot 1\left(R H_{0}\left(1-I-L_{0}\right) \geq c\right)+\left[\frac{R H_{1}\left(1-L_{1}\right)}{1+r}\right] \cdot 1\left(R H_{1}\left(1-L_{1}\right)<a\right) } \\
+ & {\left[\frac{R H_{1}\left(1-L_{1}\right)+S_{b}}{1+r}\right] \cdot 1\left(a \leq R H_{1}\left(1-L_{1}\right)<b\right) } \\
+ & {\left[\frac{R H_{1}\left(1-S_{c}\right)+S_{b}+S_{c} b}{1+r}\right] \cdot 1\left(b \leq R H_{1}\left(1-L_{1}\right)<c\right) } \\
+ & {\left[\frac{R H_{1}\left(1-L_{1}\right)}{1+r}\right] \cdot 1\left(R H_{1}\left(1-L_{1}\right) \geq c\right) . }
\end{aligned}
$$

An analogous modification is required for the learning-by-doing model. The endogeneity of the tax-subsidy parameters under the EITC coupled with the non-differentiability and non-concavity of the model greatly complicates both theoretical and empirical analysis.

\section{A Multi-period Model}

We now present models of on-the-job training and learning-by-doing in a multi-period setting. We present an heuristic analysis of the dynamic impacts of the EITC on labor supply and skill formation in both models. In most cases, as in the simple two period models previously examined, the effect of the EITC on hours worked and skill accumulation is ambiguous and depends on the balance of many offsetting forces. However, the two canonical learning models produce very different predictions about the effects of the EITC on skill formation. Rather than formally derive all of the properties of these models, we discuss the main implications of such a derivation to guide the simulations and estimation reported below.

Both models discussed in this section assume that individuals choose sequences of consumption, $C$, and leisure, $L$, to maximize total (discounted) lifetime utility. In the OJT model, individuals will also choose investment in skills, $I$, as discussed below. Government policy is described by flat income (or wage) tax rates, $\tau$, and the Earned Income Tax Credit, $S($.$) , which is a function of$ 
pre-tax labor earnings, $W$. Labor earnings depend on the amount of time spent working and the human capital level, $H$, so that $W=H(1-I-L)$. This efficiency units assumption normalizes human capital in terms of the pre-tax hourly wage rate. After-tax interest rates are denoted by $r$.

If utility is time-separable and individuals have single-period preferences $U(C, L)$ and time discount factor, $\delta$, we can write the individual maximization problem as ${ }^{13}$

$$
V(H, A)=\max _{C, L, I}\left\{U(C, L)+\delta V^{\prime}\left(H^{\prime}, A^{\prime}\right)\right\}
$$

subject to the asset $(A)$ accumulation equation

$$
A^{\prime}=(1+r) A+(1-\tau) W(1-L-I)+S(W)-C,
$$

the somewhat more general human capital equation

$$
H^{\prime}=H+F(H, I, 1-I-L)
$$

and the time constraints $0 \leq I+L \leq 1$ and $0 \leq I, L \leq 1$. We allow for the possibility that both work and investment time raise skill levels and also allow for human capital to be self-productive. We ignore the market for jobs with different learning content, leaving its development for another occasion. As suggested above, such a model would likely produce impacts somewhere between those of the two pure models presented here. We assume that workers live through age $T$ and that human and physical capital have no value at the end of life, so $\frac{\partial V_{T+1}}{\partial H_{T+1}}=\frac{\partial V_{T+1}}{\partial A_{T+1}}=0$. Where $V_{T+1}$ is the value function in period $T+1$, at birth, individuals are endowed with an initial skill level, $H_{0}$, and assets, $A_{0}$. We assume that $U(C, L)$ is separable, increasing, and concave in both of its arguments.

\subsection{On-the-Job Training}

The model of on-the-job training posits that skills are only acquired through costly time investments, $I$, so:

$$
\frac{\partial F}{\partial I}>0, \quad \frac{\partial^{2} F}{\partial I^{2}}<0, \quad \frac{\partial F}{\partial(1-I-L)} \equiv 0
$$

We also assume that $\frac{\partial F}{\partial H} \geq 0$ throughout, so that human capital is self-productive.

The EITC schedule, $S(W)$, is not differentiable and also produces a non-convex budget set for individuals. As previously noted, this feature greatly complicates the analysis. Individuals can potentially choose bundles of investment and labor supply that place them at a point of non-differentiability $(a, b$, or $c)$. Non-convexity of the budget set also implies that more than one set of $(C, I, L)$ may satisfy local conditions for a maximum.

\footnotetext{
${ }^{13}$ Let $x^{\prime}$ denote next period's value for any variable or function $x$.
} 
Fortunately, the qualitative conclusions of the two period model with fixed period-specific tax and subsidy rates continue to hold in a more general life cycle setting. The value of human capital depends positively on the number of hours worked in the future. In addition, since human capital also helps to produce further human capital, the more an individual intends to work in the future, the more he gains from raising his skill level. Alternatively, if an individual does not intend to work in the future, there is no value to investing in human capital. ${ }^{14}$ Therefore, to the extent that the EITC increases hours worked, it also increases the marginal return to human capital and skill investment.

There are three effects operating. The first two effects of the EITC on human capital investment can be broadly categorized as follows. First there is an income effect - the EITC increases total lifetime wealth like a lump-sum subsidy, which encourages the consumption of leisure and discourages work . This tends to reduce investment in skills. ${ }^{15}$ Second, there is a compensated substitution effect. By altering net wage rates, the EITC induces a substitution effect (in the opposite direction as the income effect) on hours worked. This impacts investment through current and future hours worked. There is also a direct effect of the EITC on the marginal costs of and returns to investment. Direct effects are the only ones operating in an income maximizing model. A positive marginal subsidy rate raises the marginal cost of investment by raising the opportunity cost of time, but it also increases the return to investment in skills by raising future net wage rates.

We explore each of these effects for individuals with different life cycle earnings profiles. As in the simple two period model, any labor force entry induced by the EITC program raises skill formation compared to what it would be if an individual never worked. First, consider individuals whose labor earnings would be less than $a$ in Figure 1 at all ages in the absence of the EITC. They face a positive marginal subsidy for each hour they work, which increases their net wage rate. Standard income and substitution effects would govern labor supply decisions - income effects would discourage work and substitution effects would encourage work. Depending on which effect dominates, individuals may work more or less. If the substitution effect dominates the income effect (i.e. individuals have upward sloping labor supply curves), individuals would work more in response to the EITC. As a result, the returns to human capital investment would increase, and individuals would respond by investing more in their skills. Direct effects on investment would be offsetting, since the marginal returns and marginal costs increase by exactly the same proportion. Thus on net, under these conditions agents would invest more and experience greater wage growth.

Individuals whose incomes are between $a$ and $b$ throughout their careers (in the absence of the

\footnotetext{
${ }^{14}$ If, as in Heckman (1976), the marginal utility of leisure depends positively on human capital, human capital has value even when there is no work.

${ }^{15}$ In Heckman (1976), wealth effects on labor supply do not translate into effects on investment, because human capital increases the marginal value of leisure at the same rate it increases wage rates.
} 
EITC) would receive a lump-sum subsidy of $S_{b}$ during each period of work (once again, assuming momentarily that the EITC did not alter their incentives enough to move them off the plateau region). In this case, there would be only income effects on labor supply operating through the lump sum subsidy and no direct effects on the marginal costs and returns to investment. The EITC unambiguously discourages labor supply and human capital investment through the income effect. ${ }^{16}$

Next, examine the effects of the EITC on individuals whose earnings would increase from the $(0, a)$ region to the $[a, b)$ region as they age. ${ }^{17}$ Wealth effects again tend to discourage work and investment. Income effects operating through higher wage rates in the phase-in region also discourage work and investment, while substitution effects have the opposite effect. Finally, the marginal costs of investment are increased at ages when the worker is in the phase-in region of the EITC; however, the marginal returns to investment are increased by a lesser amount, since net wage rates are only higher for a fraction of future work years. At the last age for which earnings are less than $a$, the marginal costs for investment are raised by the marginal subsidy rate, while the marginal returns to investment in skills are unaffected by the EITC since the marginal subsidy rate falls to zero in the plateau region. Unless substitution effects on labor supply are substantial in early periods, we should expect to observe reductions in investment in response to the EITC. We should also expect to observe a discontinuity in investment and hours worked profiles when individuals move into the plateau region, since the marginal cost of investment and leisure declines discontinuously. Finally, we might also observe individuals reducing their investment and hours worked profiles enough to keep income below (or at) $a$ for many years.

The effects of the EITC on investment and labor supply for individuals always within the phase-out region are different yet. Wealth effects from the lump sum income adjustment serve to discourage labor supply and investment. In addition, a lower marginal wage rate causes the agent to favor leisure if substitution effects dominate income effects. The direct effects on marginal investment costs and returns are the opposite of those that arise during the phase-in region of the schedule. Both marginal costs and returns are directly reduced by the EITC, exactly cancelling each other so the direct effect is zero. So, the net effect on investment and hours worked depends on the balance of income and substitution effects. For upward sloping labor supply curves, we would expect reductions in hours worked and investment for individuals who stay within the phase-out region. As above, the EITC may reduce investment and work enough to push early earnings into the plateau region.

For those moving from the plateau to the phase-out region of the EITC schedule, investment and hours worked are likely to be lower than they would be without the tax credit. Again, income effects discourage work and investment. Substitution effects operate as just described during the

\footnotetext{
${ }^{16}$ In fact, the EITC might discourage investment enough to lower earnings to keep people at kink $a$.

${ }^{17}$ Recall that labor earnings are generally increasing with age in the absence of the EITC.
} 
phase-out region. The increase in effective marginal tax rates associated with moving from the plateau to the phase-out region directly affects the marginal returns and costs of investment like a progressive tax. The marginal costs of investment are unaffected while in the plateau region of the schedule; however, the marginal returns to investment are reduced during later earnings periods when the individual's income places him in the phase-out region. Thus, holding labor supply constant, the EITC would tend to reduce investment in human capital at early ages. ${ }^{18}$ The disincentive effects may be so great as to reduce investment and work such that earnings never escape the plateau region.

Finally, we examine the effects of the EITC on individuals whose earnings would normally begin in the phase-out region and would increase to the point that they were no longer qualified to receive any credit (moving from $[b, c)$ to $c$ and beyond.) Income and substitution effects all operate as discussed above while earnings are in the phase-out region. The marginal costs of investment are reduced while in the phase-out portion of the schedule, since reductions in earnings caused by increases in investment are partially offset by a higher subsidy. However, the marginal returns do not decline equiproportionally, since no loss in subsidy is experienced when labor income increases during years when individuals earn more than $c$. For inelastic labor supply, the direct effects of the EITC on investment should dominate indirect effects through hours worked, so investment is encouraged by the EITC. It is possible to observe declines in hours worked and increases in investment in response to the EITC for these higher income workers. To the extent that the EITC directly encourages investment and thereby raises skill levels and wage rates later in life, it likely results in increased hours worked at older ages.

It is important to remember that investment, consumption, and hours worked are all jointly determined. Policy impacts on one dimension affect the other dimensions indirectly. We have highlighted three primary effects of the EITC on investment and labor supply decisions. The balance of these effects and the interrelationships among them are an empirical question we address below. The EITC is likely to discourage investment among low income workers starting on the first phase of the constraint and to encourage investment among workers moving from the phase-out region to beyond the schedule.

\subsection{Learning-by-Doing}

We next explore a basic experience-based model of learning-by-doing. We ignore costly time investments, $I$, and concentrate on the effects of hours worked, $h=1-L$, on human capital accumulation, assuming

$$
\frac{\partial F}{\partial I} \equiv 0, \quad \frac{\partial F}{\partial h}>0, \quad \frac{\partial^{2} F}{\partial h^{2}}<0 .
$$

\footnotetext{
${ }^{18}$ To the extent that the level of human capital increases the marginal returns to investment, investment may also decline once individuals reach the phase-out region (holding hours worked constant) due to reductions in earlier investment.
} 
Again, we consider the case where human capital is self-productive in producing skill so $\frac{\partial F}{\partial H} \geq 0$.

We first present a brief description of individual behavior in the absence of the EITC. When $\delta^{-1}=1+r$, consumption and the marginal value of assets are constant over the life cycle. In the learning-by-doing model, there are two changing forces acting on leisure which operate in opposite directions over the life cycle. As before, increasing human capital increases wages. This force implies declining leisure and increasing labor supply with age. On the other hand, the marginal value of additional labor market experience and human capital declines with age, since there are fewer future years to reap the benefits of higher wages. This second force tends to cause labor supply to decline with age. The net effect is ambiguous and will inevitably depend on the exact nature of the skill production process and preferences.

The EITC affects the marginal value of an additional hour of work today on future earnings and the increase in future earnings due to an increase in work in the current period. As with the OJT model, we discuss the effects of the EITC on labor supply and skill formation for workers with different lifetime earnings paths.

First, consider workers whose earnings would place them in the phase-in region of the EITC schedule if their labor supply paths were held at their non-EITC levels. Additional work increases the current subsidy, so substitution effects operate to increase hours worked. Income effects operate in the opposite direction, discouraging work. An increase in work today raises future skill levels and labor income. So, as long as labor earnings remain less than $a$, an increase in hours worked today will also increase the amount of subsidy received in the future (holding future hours worked constant). Of course, the balance of income and substitution effects on future labor supply will also impact the future returns to current work, since hours worked in the future affect the current marginal value of additional human capital. For upward sloping labor supply curves, the phase-in region of the EITC unambiguously increases both the current and future returns to work. As a result, labor supply and skill acquisition increase at all ages. This prediction is in sharp contrast to the negative effects on skill formation that are expected when learning is acquired through OJT. Increases in labor supply and skill may push incomes above $a$ and into the plateau region of the EITC.

The effects of the EITC on individuals with earnings in the plateau region are unambiguous. As in the OJT model, pure substitution effects are absent. Only income effects operate through the marginal valuation of wealth, causing individuals to work less at all ages. As a result, skill levels and labor incomes are reduced.

For individuals moving from the phase-in to the plateau region of EITC, all of the previously mentioned effects become relevant. Income effects discourage work at all ages. Income and substitution effects are important at early ages when income is below $a$, but skill prices are unchanged once incomes reach the plateau region. Assuming substitution effects dominate income effects, the current returns to work are raised by the EITC in the phase-in region. However, future 
returns are largely unaffected by the EITC, since the subsidy is unaffected by increases in labor income in the plateau region. The EITC encourages skill formation for those in the first phase by raising the current returns to work. When coupled with the negative wealth effects over the plateau region, we should expect smaller effects of the EITC on labor supply and skill formation for individuals moving beyond the phase-in region than we observe for those remaining in that region.

While the phase-in region encourages work and skill formation by raising the current and future returns to an hour of work, the phase-out region has the exact opposite effect. It reduces the net wage rate which reduces both the current and future returns to work. The lump sum transfer of wealth also serves as a disincentive for work. As long as labor supply curves slope upward, individuals with incomes in the phase-out stage of the EITC schedule will work less and produce fewer skills than they would in the absence of the EITC.

The same is true for individuals moving from the plateau region to the phase-out region. Income effects operate to discourage work. While the current returns to work at early ages are largely unaffected by income and substitution effects, the future returns to current work are diminished by the EITC. This is because increases in work today raise future wage rates. The resulting increases in future earnings are partially offset by a reduction in the income subsidy when labor income exceeds $b$. As a result, labor supply declines and less skill is acquired.

Finally, work and skills are discouraged for individuals moving off the EITC schedule from the phase-out region (again, assuming upward sloping labor supply curves). Wealth effects discourage work. While in the phase-out region, current returns from work are reduced by the EITC, since for each additional dollar earned, a fraction of the tax credit is lost. Future returns are largely unaffected, since no subsidy is received in periods when labor income is above $c$. So, while those moving from the plateau to the phase-out region work less because the future returns to work were diminished, workers beginning in the phase-out region work fewer hours because the current returns are lower.

As long as labor supply curves are upward sloping, the EITC tends to encourage work and skill formation for the lowest income workers - those who spend some of their lives in the phase-in region of the schedule. For all other workers with incomes always above $a$, the EITC discourages work and reduces the accumulation of skills. Individuals in the phase-out region of the EITC are most discouraged from work, since it reduces both the current and future returns to skills.

\subsection{Comparing OJT and LBD}

The two pure models of skill formation sometimes predict quite different responses of investment to the EITC. In the OJT model, the EITC has little effect on skill formation for workers in the phase-in region (though, if substitution effects dominate for labor supply the EITC will raise investment and work for affected persons), while the LBD technology produces positive effects on 
skill formation. For individuals moving off the EITC schedule from the phase-out region, the OJT model predicts an increase in skill accumulation, while the LBD model predicts a decline. The effects on learning are reversed in both models for individuals moving from the phase-in region to the plateau region. Workers with earnings in other regions of the EITC schedule respond with reductions in skill acquisition in both models, though the magnitudes of those responses likely differ.

As was true for the two period models, few sharp analytical predictions about the magnitudes of these effects can be made without some knowledge of parameter values for preferences and the skill production technology. We turn next to an initial empirical exploration using specific versions of both human capital models, exploring the effects of the EITC on skill formation and labor supply.

\section{Grounding The Model in Data}

The appropriate way to estimate the impact of the EITC program on earnings and labor supply is to estimate the model imposing the full constraints from the EITC schedule and from economic theory. We do not undertake the formidable task of full structural estimation in the presence of the EITC in this paper, leaving that for another occasion. Instead, in this paper we estimate parameters for individual preferences and skill functions using data from a time period when the EITC was a small-scale program for low skilled workers. The empirical results we offer are necessarily more illustrative than definitive, but provide some guidance on the likely magnitudes of the effects of the EITC on skill formation.

Responses to the EITC depend critically on where individuals lie on the EITC schedule. We, therefore, consider a number of different types of workers. In particular, we use data on wages and hours worked from the 1980 March CPS to estimate preference and human capital production parameters for women classified by race (black and white) and education (less than 10 years, 10-11 years, and 12 years of schooling). The EITC provided only modest assistance in the early 80 's and was primarily designed as an offset for the social security payroll tax for low income workers.

Because the EITC schedule is not everywhere differentiable and does not yield a convex budget set, simple methods for solving the individual's problem cannot be used for our simulations. To simplify the problem, we break the life cycle into 10 periods. Beginning at age 18, individuals are grouped by 5 year periods through age 67. See Appendix $\mathrm{C}$ for an explicit discussion of the algorithm used to solve the optimization problem, and to guard against local optima.

We now present the empirical specification for individual preferences and human capital production technology that we use in our calibration and simulations. We assume the following separable utility function 


$$
U(C, L)=\frac{C^{\gamma+1}}{\gamma+1}+\psi \frac{L^{\sigma+1}}{\sigma+1}
$$

where $\gamma$ and $\sigma$ are both strictly negative and $\psi$ is positive. We choose the conventional Ben Porath (1967) human capital production function for our OJT model:

$$
H^{\prime}=H+B(I H)^{\alpha},
$$

where $B>0$ and $0<\alpha<1$. Heckman, Lochner and Taber (1998) present some evidence in support of this form of the OJT model for men and women. There is less discussion in the empirical literature about the specification of learning-by-doing function. One interpretation of a "Mincer" earnings function writes current earnings as a quadratic in cumulative work experience:

$$
H=H_{0}+\beta_{0} X+\beta_{1} X^{2}
$$

where $X=\sum_{\tau=1}^{t-1} h(\tau)$ represents total work experience accumulated to date $t$. We expect $\beta_{0}>0$ and $\beta_{1}<0$, which would yield increasing and concave wage profiles. ${ }^{19}$

The quadratic in experience earnings function is familiar from the Mincer (1974) model; although his justification for the specification is as an approximation to the Ben Porath (1967) model. In a single cross section of wages, it is impossible to distinguish between the two models, and in practice, labor economists treat these models interchangeably despite their often contradictory implications about the effects of wage subsidies on skill formation.

Unfortunately, the available data do not allow us to identify all of the parameters of the model since we lack information on consumption and wealth holdings. Since the EITC targets low income workers, initial assets, $A_{0}$, are assumed to be zero for all individuals. We assume $\gamma=-0.9$, yielding an intertemporal elasticity of substitution for consumption of 1.11 . We take perfect credit markets as our base case environment, and assume an interest rate of $r=0.6105$, which corresponds to an annual interest rate of $10 \%$ (each period represents five years). We assume a rate of time preference, $\delta=.6219$, which yields slightly rising consumption profiles. These values are consistent with the parameters reported by Browning, Hansen, and Heckman (1999).

We use weighted non-linear least squares to estimate the remaining parameters of both human capital models. We estimate separate parameters, $\Theta$, for each type of worker, minimizing

$$
\sum_{i=1}^{n} \sum_{t=1}^{10}\left[Q_{t}^{w}\left(w_{i, t}-w_{t}(\Theta)\right)^{2}+Q_{t}^{h}\left(h_{i, t}-h_{t}(\Theta)\right)^{2}\right],
$$

where $w_{i, t}$ and $h_{i, t}$ are wage rates and hours worked ${ }^{20}$ for individual $i$ of age $t$ from the CPS, and $w_{t}(\Theta)$ and $h_{t}(\Theta)$ are wage rates and share of time worked (which includes time spent working

\footnotetext{
${ }^{19}$ Shaw (1989) fits such a model. Altug and Miller (1998) estimate a more general model in which both employment and work hours produce skill. Our specification differs from Mincer's because we use levels of wages while he uses logs.

${ }^{20}$ We use total hours worked divided by 5,840 (corresponding to 16 hours a day) to express hours in an amount corresponding to a share of available time.
} 
and investing in skills in the OJT model) predicted by the model for a person age $t$, with the parameter vector $\Theta$ defining preferences and the human capital production function. In our OJT model, $\Theta$ includes $\psi, \sigma, B, \alpha$, and $H_{0}$; in our LBD model, $\Theta$ includes $\psi, \sigma, \beta_{0}, \beta_{1}$, and $H_{0}$. The weights $Q_{t}^{w}$ and $Q_{t}^{h}$ are equal to the inverse of the variance of wages and hours worked (respectively) for that demographic group. ${ }^{21}$

Tables D-1 and D-2 in the appendix present the estimated parameter values for both models. The $\psi$ parameter determines how much an individual values leisure relative to consumption, and $\sigma$ determines the intertemporal elasticity for labor supply. The estimates from the OJT model suggest that labor supply is quite inelastic for all types as seen by the large negative values for $\sigma$. Estimates of $\sigma$ from the LBD model also show inelastic labor supply, although they are generally smaller than the OJT estimates. These estimates are within the range of estimates found in other studies of intertemporal labor supply elasticities. (See Browning, Hansen, and Heckman, 1999, for a recent summary of estimated labor supply elasticities in the literature.) Tables D-3 and D-4 reveal that our LBD specification tends to fit the data better (in terms of the weighted sum of square errors criterion) for more educated women, while the OJT specification fits the data better for less educated women.

There is considerable heterogeneity in estimates of the human capital production parameters across groups, reflecting differences in life cycle earnings profiles. Initial stocks of human capital are greatest for high school graduates. Patterns for other parameters are not so easily detected. In the LBD model, initial skill levels are more homogeneous across all groups (ranging from 2.9 to 3.8 as compared to 3.0 to 4.2 in the OJT model). Estimates of $\beta_{0}$ tend to be greater for the more educated workers, reflecting greater returns to experience. The difference between the two sets of $H_{0}$ estimates is due to on-the-job investment in the OJT model. While initial earnings are quite similar across all groups - note the similarity in $H_{0}$ estimates in the LBD specification - the steeper wage profiles among more educated workers implies that investment levels are greater for them in the OJT specification. Greater investment among more educated women suggests that their initial human capital levels are larger than their initial wage levels. So, even though initial wages are similar across education groups, initial skill levels vary more in the OJT specification due to differences in early on-the-job investments. A major difference between the two models lies in the estimated elasticity of intertemporal substitution in leisure demand with respect to the wage, which is the same as the Frisch elasticity in the separable preference specification we use.

\footnotetext{
${ }^{21}$ If hours worked and wages in each period are measured with independent and normally distributed errors with zero mean, this is equivalent to maximum likelihood. The parameter estimates are similar when different weights are used. We do not claim optimality for the estimator.
} 


\section{Simulating the Effects of the EITC}

In this section, we use the estimated models to simulate the effects of the 1994 EITC schedule (for families with two children) on individual decisions over the life cycle using the parameter values described in the previous section. Since we only examine the effects of the program on a single worker, we implicitly assume that there is no other source of labor income (i.e. from a spouse). We begin by analyzing the effects of the EITC on skill formation from the OJT model. We then simulate the effects from the LBD model.

\subsection{On-the-Job Training}

The effects of the EITC depend on an individual's earnings profile. Table 5 reports the EITC region for the initial and final earnings levels for less educated women, ${ }^{22}$ who tend to begin their careers in the phase-in or plateau region and finish in the plateau or phase-out region.

To show the heterogeneity in impacts of the EITC, we focus on two classes of women with low levels of education. In particular, we study the effects of the EITC on human capital investment, leisure, skill levels, wage rates, and wage income for white females with 12 years of education and non-white females with less than 10 years of schooling. As shown in Table 5, they represent workers who move from the plateau region to the phase-out region (or kink between the plateau and phase-out region) and workers who spend their entire careers in the phase-in region. The previous section suggests that the EITC will have differential impacts on investment and labor supply among these subgroups of women.

We first consider the effects of the EITC on the investment $(I)$ of women who would work even in the absence of the EITC, considering entry effects later. As predicted, Figure 2 reveals that investment is reduced by introduction of the EITC for both types of female workers. The solid lines represent investment paths in the absence of the EITC; the dotted lines report investment paths after introducing the EITC.

Hours worked for these workers are presented in Figure 3. Without the EITC, hours worked would generally rise with age. However, with the EITC in place, life cycle profiles for work hours are substantially flatter, even falling over later years. Hours worked increase for the less educated non-white females while their earnings remain in the phase-in section; however, as earnings reach or move into the plateau region, hours worked decline due to the wealth effects induced by the lump sum subsidy. The discontinuity occurs as they reach a kink between different regions of the schedule. For white high school graduates, hours worked initially rise until earnings reach the kink between the plateau and phase-out regions. At that point, hours worked decline due to the high marginal subsidy rate, keeping earnings right at the kink.

\footnotetext{
${ }^{22}$ The earnings levels are computed for our OJT simulations when individuals face the EITC schedule. The regions differ only slightly if we considered earnings in the absence of the EITC.
} 
Figure 4 shows the cumulative effects of on-the-job investments on human capital levels. As could be predicted from Figure 2, white female high school graduates experience the largest impact of the EITC on skills. Human capital levels are reduced by more than $10 \%$ at the end of their careers. Reductions are smaller, but noticeable, for the less educated non-white women.

The resulting effects of the EITC on life cycle wages can be seen in Figure 5. Wage profiles flatten as investment declines. Notice that the initial effects on wages, which rise initially as investment rates decline, do not reflect the long-term effects. This suggests the importance of a dynamic analysis. Finally, the combined effects of the EITC on investment, hours worked, and skill levels are translated into impacts on wage income, as seen in Figure 6. The impacts on wage income are generally exaggerated versions of the impacts on wage rates. Both figures show how workers maintain earnings at a kink in the EITC by adjusting hours of work and investment in skills.

The impacts on lifetime earnings can be seen in Table 6. The EITC reduces labor market earnings for all workers, with the largest effects observed for the more educated women, who begin their careers in the plateau region. The total lifetime amount of subsidy uneducated women receive is large, reaching $\$ 20,000$ in present value. For high school graduates, nearly $1 / 2$ of the subsidy is offset by a decline in labor earnings. Thus, the program reduces hours of work among workers and also reduces their skill levels. For the majority (the number of qualifying high school graduates far exceeds the number of dropouts), it replaces earnings with income from "welfare". Most of these earnings declines reflect increases in leisure, as decreases in skills are generally offset by reductions in investment costs.

In most cases, the short-term effects of the EITC are very different from the long-term impacts. For the first few periods, the least educated women increase their hours worked and only slightly reduce investment in response to the EITC. Wages increase initially. The long-term impacts are far different. Investment declines still further and hours worked fall precipitously. Skill levels and wage rates also decline substantially. This reveals the dangers of using short-term responses to predict the long-term consequences of the EITC on individual well-being. Only a dynamic analysis like the one we adopt can shed light on the long-term outcomes we might expect.

Thus far, we have only examined the effects of the EITC on those who would have worked in the absence of the program. As suggested by the analysis of Eissa and Liebman (1996), the EITC may also encourage individuals to work who otherwise would not. Table 7 reports the annual compensation required to make each of the demographic groups we analyze indifferent between working and not working. These calculations compare the utility of full-time leisure and a constant annual income with the income and leisure associated with working for each group. The table reveals that uneducated women can be easily induced to stay out of the labor market for small sums of 'welfare' payments. The EITC only marginally reduces those sums, suggesting small entry effects should be expected. 
To estimate the total effect of the EITC program on skills, it is necessary to consider potential entry effects. Eissa and Liebman (1996) estimate that the 1986 expansion of the EITC increased employment of single women with children by about three percentage points. We explore the consequences for skill investment of a range of potential employment effects (1-7\%) to determine the total impact of the EITC on average skill levels. ${ }^{23}$

Table 8 reports employment rates based on the 1994 March CPS and average human capital (both potential, $H$, and utilized, $H(1-I-L)$ ) as estimated above, assuming an equal distribution of workers across all age groups. Utilized human capital reflects earnings. The reported average human capital levels are inclusive of non-workers who are assumed to have potential skill levels equal to $H_{0}$ and to supply zero skills to the market. Skill and skill supplied to the market increase with education levels.

In Table 9, we use our estimated preference and human capital parameters to examine the effects of increasing employment on skill formation, using a range of values for the estimated entry effect. Column 1 reports the raw difference in average lifetime skill levels for workers and nonworkers. We assume that those who do not work remain at their initial skill levels throughout their lives, while those induced to work by the EITC accumulate skills using the technology estimated in this paper following the human capital accumulation paths depicted in Figure 4. Columns 2-5 report the estimated impact on human capital of increasing employment by different percentage points. These entry effects increase the average skill level in the economy by anywhere from .003 to .07 for different women. (Note that these are differences in potential wage rates.) These must be balanced against the disincentive effects on those who are already working, as reported in columns 6 and 7. Column 6 reports the change in skills for workers attributable to the EITC, while column 7 weights that amount by the employment rate for the particular group. When determining the total effect on average skill levels for any demographic group, simply add the effect on skill from increased employment (from one of columns 2-5) to the effect on current workers (column 7).

Based on the evidence in the literature, a plausible upper bound entry effect is a 3-5 percentage point increase. For dropouts, the skill accumulation effects at the intensive and extensive margins are of similar magnitudes. For all but white women with 10-11 years of schooling, the negative effects at the intensive margin outweigh the positive entry effects for entry effects as large as $7 \%$. Clearly, estimating the impact of the EITC on average skill levels requires knowledge of both employment effects and the effects on current workers. Both effects are important and they operate in different directions.

The bottom panel predicts how a universal EITC program (regardless of spousal earnings

\footnotetext{
${ }^{23}$ In principle, one could estimate the employment effects using Table 7 and a distribution of potential welfare (or other income) payments to workers. The entry effect will depend on (1) how much the EITC raises the annual compensation necessary to make individuals indifferent between working and not working; and (2) how many individuals are currently at the margin.
} 
and child status) would impact the skill levels of women with 12 years of schooling or less using various assumptions about the program's impact on labor force entry. In this panel, we weight the effects of the EITC for each group including employment effects and those for current workers by the proportion of the population in that group (as reported in Table 8). Overall, the EITC reduces potential skill levels by about $-0.2(7 \%)$ among low educated women, even if entry effects are extremely large.

Table 10 repeats these calculations for skills supplied to the market (earnings $=H(1-I-L)$ for workers and zero for non-workers) rather than total skills, $H$. The positive impacts of the EITC due to entry are generally greater when compared with the average levels of utilized skill (reported in Table 8). The effects at the intensive margin for workers are more similar in the two tables. The net impact of the EITC on aggregate utilized human capital is negative (about -10\%), even when employment effects are large, since the effects on high school graduates dominate those for lesser educated female workers. So, plausible estimates of the impact of the EITC on employment suggest that the EITC would decrease both potential and utilized skill levels among women with no college experience.

\subsection{Learning-by-Doing}

The effects of the EITC on skill formation among those who would work in the presence or absence of the program are much smaller in our estimated LBD specification. Even though hours worked are substantially reduced for white female high school graduates, as seen in Figure 7, human capital accumulation is not. See Figure 8. The least educated non-white females are encouraged to work by the EITC, since they spend their careers in the phase-in region where both future and current returns to work are rewarded by the credit. Table 11 shows where along the EITC schedule individuals begin and end their working careers. Most of the entries are similar to those discussed for the OJT model (Table 5).

The small effects of the program on skill formation are largely due to the specification of the skill acquisition function. In our specification, human capital is a function of cumulative hours worked. If human capital peaks at some level of total hours worked within the span of possible values, then fewer hours worked each year mean that the critical level is reached later in life. Therefore, wages and skills peak later, but the height of the peak is the same. Since we specify earnings (and skills) as a quadratic function of total experience, and earnings peak at around age 45-50 for most workers, reductions in hours worked caused by the EITC (or its expansion) simply cause a worker's earnings to peak at a later age. The EITC does not reduce hours enough so that earnings never reach their peak. If the influence of past hours worked on current skill production depreciated quickly, we would find larger effects of the EITC on skill formation, since earnings need not peak or may peak at a different level. In any case, impacts on skills should be negative for all workers who do not spend part of their careers in the phase-in region. That is a universal 
feature of a learning-by-doing model.

Wages are the same as skill levels in the LBD model. Figure 9 illustrates the weak estimated effect of marginal hours of work on hourly wages. Huge changes in hours of work are required to change hourly wages by more than a few cents for most workers. Also, notice that beyond a certain threshold, additional work reduces skills due to the quadratic specification in total accumulated experience. Because human capital levels are largely unaffected by the program, the effect of the EITC on wage earnings, as shown in Figure 10, are essentially due to adjustments in current hours of work. Only non-white females with less than 10 years of education earn more as a result of the EITC program.

Table 12 translates these earnings effects into the lifetime present value of earnings. Earnings reductions are typically much larger than those predicted from the OJT model, and for high school graduates, reductions in earnings are more than one-half the supplement to earnings offered by the EITC. For the least educated women, however, the EITC substantially augments earnings with little offset from changes in behavior. The least educated non-white women actually experience increases in labor earnings.

Table 13 shows the welfare compensation necessary to make workers indifferent between working and not working in our LBD specification. As in the OJT model, the required sums are small, and the EITC only marginally changes those reservation values. Table 14 is the LBD analog of Table 8, reporting employment rates and average skill levels for the different women. Tables 14 and 15 examine the impacts of the EITC on average skills in the economy at the extensive margin (entry effects) and at the intensive margin (for workers). The entry effects are similar to those produced by the OJT model. Impacts on the potential skills of workers (at the intensive margin) are generally small and positive, while effects on skills actually supplied to the market are large and negative as observed with the OJT model. Average potential human capital levels are predicted to increase with the introduction of the EITC, since entry effects dominate. However, utilized skills are predicted to decline for all but the least educated, as the negative effects of the EITC on workers dominate positive entry effects. While the entry effects on skill formation are quite similar to those found for the OJT model, changes in potential skill among workers caused by the EITC are typically much smaller than in the OJT model. This could have been anticipated from a comparison of the strong effect of the EITC on human capital in the OJT model (Figure 4) and the weak effect in the LBD model (Figure 8). The EITC, therefore, is predicted to have slightly larger impacts on average potential skill levels when the LBD model is used. In contrast, the LBD model often produces more negative impacts on the utilized skills of workers than the OJT model (compare the final columns of Tables 10 and 16). This is largely due to the substantial effects of the EITC on hours worked in the LBD model. In both models, however, the effects of the EITC on the total utilized skills of women with low levels of education are dominated by the negative effects on workers even when employment effects are quite large. For small entry 
effects (of 1 percentage point), impacts on skills supplied to the market (i.e. earnings) are as large as $18 \%$ of average levels for the LBD model, whereas the OJT model predicts slightly smaller responses.

\subsection{Accounting for Life Cycle Eligibility Due To Children}

Thus far, we have focused on the impacts of the EITC ignoring other family income or the number of qualifying children. The simulation results presented in the previous sections compare the case of extending the EITC to all workers vs. removing the EITC for all workers.

The EITC has different schedules based on the number of children living in the household. This seemingly harmless qualification can drastically affect estimated behavioral responses to the EITC, since families cannot expect to receive the credit (or at least the larger credit for parents) for their entire working careers unless they continue to have qualifying children. In general, families can only expect to receive the credit for 20-30 years, depending on how many children they have and how they space them. Additional sources of family income alter the analysis in a predictable way to reduce eligibility. We focus on the less obvious effects of current child requirements.

Modifying the analysis to account for limited time periods of EITC qualification substantially changes the implications for workers ending their careers in the phase-in or phase-out regions of the EITC. If termination of EITC eligibility due to failure to meet the child requirement occurs in the phase-in region, future returns to investment in skills are no longer subsidized. Only costs of investment are increased, so the disincentive effects reduce skills. In our simulations, the EITC only has moderate negative impacts on investment for the least educated women due to income effects on labor supply. It will have substantially larger negative impacts on their skill formation if they cannot receive the benefits from increased subsidy levels later in their careers, as would be the case if their children grow too old for them to qualify for the credit. On the other hand, for workers ending their careers in the phase-out region, termination of the credit due to aging children removes the tax on returns to investment that causes more educated female workers to scale back their investments. For workers who end their careers with earnings too high to qualify for the credit, the child restriction is of little consequence.

\section{Evidence on OJT vs. LBD}

We have, thus far, discussed the varied impacts of the EITC on skill formation and wage growth using two standard human capital models. The OJT and LBD models predict opposite effects on investment and wage growth. While changes in the EITC over time could potentially be used to test which model better represents the skill formation process, the complexity of the program makes this extremely difficult to do in practice. 
In Heckman and Lochner (2002), we use data from the Seattle and Denver Income Maintenance Experiments to estimate the effects of a short-term (3 years) increase in marginal income tax rates on wage growth. These experiments, conducted in the 1970s, randomly assigned low income families to different negative income tax schedules (for 3-5 years) that included marginal tax rates ranging from $50 \%$ to $80 \%$. While both models of human capital formation predict that the short-term income transfers and high marginal tax rates associated with the experiment should, at least temporarily, reduce labor supply, the OJT and LBD models predict opposite effects on skill formation and wage growth. ${ }^{24}$ As discussed in Section 2.1, the OJT model predicts that a short-term increase in income tax rates will encourage human capital investment and increase wage growth while the LBD model predicts the opposite. The estimates by Heckman and Lochner (2002) suggest that wage growth rates were about $10 \%$ lower among male treatments facing the negative income tax schedules than among male controls facing the standard U.S. federal tax schedule. This finding suggests that wage growth decreases with increases in short-term tax rates, consistent with the theory of learning-by-doing and not on-the-job training.

\section{Conclusions}

The EITC has been justified on the grounds that it transfers income to the working poor, particularly struggling mothers, without substantially reducing their incentives to work. It also stimulates non-workers to work. This paper explores the impact of the EITC on incentives to work and accumulate skills in two different models of human capital formation. Correct specification of the skill formation process is critical to understanding the effects of the EITC on skills, since different models produce very different predictions of its effects on skill formation. Theory is ambiguous about the effects of the EITC on skill formation, so it is necessary to undertake an empirical analysis of the question.

In order to measure the empirical effects of the EITC, preference and human capital production parameters for two canonical models of skill formation are estimated from the wage and hours worked profiles of less educated working women using the 1980 CPS. Those parameters are then used to predict individual responses in labor supply and investment caused by introduction of the EITC.

We find that in a training model in which skills are produced by costly time investments (OJT), the EITC encourages skill investment for workers who begin their careers in the phase-out region and end their careers above the EITC income cut-off. Time spent working is much lower during the phase-out region and slightly higher beyond that region. None of the less educated women we study earn this much. Among female high school dropouts and graduates, who spend their careers within the income limits of the EITC schedule, the EITC substantially reduces investment

\footnotetext{
${ }^{24}$ Results in Robins and West (1980a,b) empirically support the prediction for labor supply.
} 
and skill formation. Labor supply is initially higher for workers facing the EITC schedule, but the life cycle profile is flatter and hours worked are lower later in the life cycle.

Using our estimated experience-based learning-by-doing model of skill formation, we find very different impacts from the EITC. While labor supply is generally reduced by the EITC (by as much as $20 \%$ in some periods for working women in the phase-out and plateau regions), the effects of the EITC on skill formation are quite small. Skills marginally increase among the least educated dropouts, whose earnings remain within the phase-in region of the schedule.

Impacts of the EITC on skill formation at the extensive (or entry) margin are essentially the same for both skill models. To the extent that the EITC raises employment rates by making work more attractive, it also raises skill levels. For any given increase in work rates, the increase in human capital supplied to the market from increased employment does not depend much on how those skills are formed. In the OJT model, the impacts on skill formation of the EITC for entrants and for those who would work under any event, are of the same order of magnitude, but of the opposite sign. Marginal changes among workers tend to dominate, causing the EITC to decrease potential and utilized skills among less educated women. For the LBD model, the entry effects on the formation of potential market skills are much stronger than the effects on those who would work in the presence or absence of the program, whose human capital is only marginally affected. The greatest differences between models of skill formation are found for workers at the intensive margin deciding how much to work and invest in additional skills. When considering utilized skills, the two models are largely in agreement, predicting negative impacts of the EITC on average earnings levels. We estimate declines as large as $18 \%$ of current average utilized skill levels if entry effects are small.

The empirical evidence presented in this paper can only be regarded as suggestive rather than definitive. Like the rest of the literature, we have not yet produced a reliable estimate of the effect of the EITC program on employment among those who would not work in its absence. Our estimated entry effects are simply educated guesses about plausible magnitudes of the response. However, unless the true entry effects are extremely large, negative effects of the EITC on current workers are likely to dominate the positive effects through induced entry.

Much more empirical work is required to determine the exact mechanism of skill formation and how learning opportunities are priced in the market. We have compared two simple specifications. The EITC has large effects on training in an OJT model but weak effects on labor supply. It has little effect on skills and larger labor supply impacts when studied within the LBD model we employ.

A more general model of skill formation that recognizes the existence of markets for jobs and that derives explicit solutions for the prices of jobs with different learning opportunities would be desirable. We have demonstrated the importance of knowing the exact mechanism by which skills are produced and how jobs with different learning content are priced. The exact specification of 
preferences and skill formation requires much further study before we can be sure which model is more appropriate.

At our current level of understanding, the evidence shows that the EITC has a negative impact on the average skill levels of less educated women. (However, it may have large effects on other groups of workers as shown in Heckman, Lochner and Cossa, 1999.) This is because the positive impacts due to entry are typically dominated by the negative effects on those who would work in the presence or absence of the EITC program. Furthermore, some workers respond to the EITC by increasing their skill levels, while others reduce their skills. In the empirically plausible range, the program reduces earnings among less educated women. This effect operates primarily through (long-term) labor supply disincentives. The EITC may have substantial effects on most workers, while only having a minor effect on average skill and wage levels. Econometric methods that only identify mean effects of programs like the EITC miss the larger picture. 


\section{References}

[1] Altug, S., and R. Miller, "The Effects of Work Experience on Female Wages and Labor Supply," Review of Economic Studies, 65(222), 45-67, 1998.

[2] ______, "Household Choices in Equilibrium," Econometrica, 58(3), 543-570, 1990.

[3] Becker, Gary, Human Capital, New York: Columbia University Press, 1964.

[4] Ben Porath, Y., "The Production of Human Capital and the Life Cycle of Earnings," Journal of Political Economy, 75(4), 352-365, 1967.

[5] Browning, M., L. Hansen, and J. Heckman, "Micro Data and General Equilibrium Models," in J. Taylor and M. Woodford, eds., Handbook of Macroeconomics. North-Holland Press, Amsterdam, 1999.

[6] Eissa, N. and J. Liebman, "Labor Supply Response to the Earned Income Tax Credit," The Quarterly Journal of Economics, 111(2), 605-637, 1996.

[7] Hamilton, S., Apprenticeship for Adulthood, New York: Free Press, 1990.

[8] Heckman, J., "Three Essays on Household Labor Supply and the Demand For Market Goods," Chapter 1, Ph.D. Dissertation, Princeton University, 1971.

[9] Heckman, J., "Life-Cycle Model of Earnings, Learning, and Consumption," Journal of Political Economy, 84(4):S11-S44, August 1976.

[10] Heckman, J. and L. Lochner, "Testing between On-the-Job Training and Learning-by-Doing Models of Skill Formation,” Working Paper, University of Rochester, 2002.

[11] J. Heckman, L. Lochner and Cossa, R., "Wage Subsidies and Skill Formation: A Study of the Earned Income Tax Credit," Working Paper, 1999.

[12] Heckman, J., L. Lochner, J. Smith and C. Taber, "The Effects of Government Policy on Human Capital Investment and Wage Inequality," Chicago Policy Review, 1(2), 1-40, 1997.

[13] Heckman, J., L. Lochner, and C. Taber, "Explaining Rising Wage Inequality: Explorations with a Dynamic General Equilibrium Model of Labor Earnings with Heterogeneous Agents," Review of Economic Dynamics, 1(1), 1998.

[14] Killingsworth, M., "Learning By Doing and Investment in Training: A Synthesis of Two Rival Models of the Life Cycle," Review of Economic Studies, 49(2), \#156, 263-272, 1982.

[15] Lochner, L., "A Life-Cycle Model of Human Capital and Crime: Estimating Deterrent Effects of Wage and Education Subsidies," Ph.D. Dissertation, University of Chicago, 1998. 
[16] Mincer, J., Schooling, Experience and Earnings, New York: Columbia University Press, 1974.

[17] Phelps, N., Rewarding Work, Harvard University Press: Cambridge, 1997.

[18] Robins, P. and R. West, "Program Participation and Labor-Supply Response," The Journal of Human Resources, 15(4), 499-523, 1980a.

[19] Robins, P. and R. West, "Labor-Supply Response Over Time," The Journal of Human Resources, 15(4), 499-523, 1980b.

[20] Rosen, S., "Learning and Experience in the Labor Market," The Journal of Human Resources, 7(3), 326-342, 1972.

[21] Shaw, K., "Lifecycle Labor Supply with Human Capital Accumulation," International Economic Review, 30, 431-456, 1989.

[22] Weiss, Y., "On the Optimal Lifetime Pattern of Labour Supply," Economic Journal, 82(328), 1293-1315, 1972. 


\section{Appendix A}

Table A-1: Definition of EITC Regions for CPS Calculations

\begin{tabular}{lc}
\hline \hline Region & Income Range \\
\hline I (phase-in) & $W<0.95 a$ \\
II (first kink) & $0.95 a \leq W<1.05 a$ \\
III (plateau) & $1.05 a \leq W<0.95 b$ \\
IV (second kink) & $0.95 b \leq W<1.05 b$ \\
V (phase-out) & $1.05 b \leq W<0.95 c$ \\
VI (third kink) & $0.95 c \leq W<1.05 c$ \\
VII (no credit) & $1.05 c \leq W$ \\
\hline The values of a,b,c are obtained from Table 1
\end{tabular}




\section{Appendix B}

\section{Nonconcavity of the Reward Function in the Ben Porath model in the Presence of an EITC Program}

For simplicity, set $R=1, r=0, H_{0}=1$. Then consider $V(I)$ for a program where there is either a phase-out range or a no program range. For $I>k$, we assume that a person is in the phase-out range (branch 3). For $I \leq k$, we assume that a person is in the no program range (no tax or subsidy). Using $\tau$ as the phase-out tax rate, we may write $V(I)$ for two values of $I_{1}$ and $I_{2}$, which in the second period place the individual in the no-EITC zone.

$V\left(I_{1}\right)=(1+\tau)\left(1-I_{1}\right) 1\left(I_{1}>k\right)+\left(1-I_{1}\right) 1\left(I_{1} \leq k\right)+F\left(I_{1}\right)$

$V\left(I_{2}\right)=(1+\tau)\left(1-I_{2}\right) 1\left(I_{2}>k\right)+\left(1-I_{2}\right) 1\left(I_{2} \leq k\right)+F\left(I_{2}\right)$

We can always find such values of $I_{1}$ and $I_{2}$. (This is trivial if the agent starts in the no program range.) Provided investment is sufficiently productive, we can move the agent from the phase-out range to the no program range. This requires that we find values of $I_{1}$ such that $\left(1-I_{1}\right)<$ $c, \quad F\left(I_{1}\right)+1>c$ so $1-c<I_{1}, F\left(I_{1}\right)>c-1$. Assuming $F$ is monotonically increasing $\operatorname{Max}\left\{1-c, F^{-1}(c-1)\right\}<I_{1}$. Then letting $\bar{I}=\lambda I_{1}+(1-\lambda) I_{2}, 0 \leq \lambda \leq 1$,

$$
\begin{aligned}
V(\bar{I}) & =(1+\tau)(1-\bar{I}) 1(\bar{I}>k)+(1-\bar{I}) 1(\bar{I} \leq k)+F(\bar{I}) \\
& =\tau(1-\bar{I}) 1(\bar{I}>k)+(1-\bar{I})+F(\bar{I}) .
\end{aligned}
$$

Next, we obtain

$$
\begin{aligned}
\lambda V\left(I_{1}\right)+(1-\lambda) V\left(I_{2}\right) & \\
= & \lambda \tau\left(1-I_{1}\right) 1\left(I_{1}>k\right)+\lambda\left(1-I_{1}\right)+\lambda F\left(I_{1}\right) \\
& +(1-\lambda) \tau\left(1-I_{2}\right) 1\left(I_{2}>k\right)+(1-\lambda)\left(1-I_{2}\right)+(1-\lambda) F\left(I_{2}\right) \\
= & (1-\bar{I})+\tau\left(\lambda\left(1-I_{1}\right) 1\left(I_{1}>k\right)\right)+\tau\left((1-\lambda)\left(1-I_{2}\right) 1\left(I_{2}>k\right)\right) \\
& \quad+\lambda F\left(I_{1}\right)+(1-\lambda) F\left(I_{2}\right) .
\end{aligned}
$$

$V(I)$ is concave if

$$
V(\bar{I}) \geq \lambda V\left(I_{1}\right)+(1-\lambda) V\left(I_{2}\right),
$$

or

$$
\begin{aligned}
& \tau(1-\bar{I}) 1(\bar{I}>k)+F(\bar{I}) \geq \\
& \tau\left[\lambda\left(1-I_{1}\right) 1\left(I_{1}>k\right)\right)+\left((1-\lambda)\left(1-I_{2}\right) 1\left(I_{2}>k\right)\right]+\lambda F\left(I_{1}\right)+(1-\lambda) F\left(I_{2}\right) .
\end{aligned}
$$

Clearly, $F(\bar{I})-\lambda F\left(I_{1}\right)-(1-\lambda) F\left(I_{2}\right) \geq 0$ by concavity in $F(I)$. However, it is not necessarily true that for $\tau>0$

$$
(1-\bar{I}) 1(\bar{I}>k) \geq\left[\lambda\left(1-I_{1}\right) 1\left(I_{1}>k\right)+(1-\lambda)\left(1-I_{2}\right) 1\left(I_{2}>k\right)\right]
$$

Provided $I>0$, it is possible that $\bar{I}<k$, but either $I_{1}$ or $I_{2}>k$. Then the concavity condition may or may not hold. Thus for certain ranges of values of investment we may obtain concavity of the reward function while for others we do not. If investment is sufficiently productive, the 
contribution of $F(\bar{I})-(\lambda) F\left(I_{1}\right)-(1-\lambda) F\left(I_{2}\right)$ may offset the non-concavity arising from the jump in the indicator functions. 


\section{Appendix C \\ Solution Algorithm for Individual Optimization Problem}

Problems with discontinuities and a non-convex budget set require that non-standard solution methods be employed in solving the individual's optimization problem. This is why we reduce the life cycle problem to ten periods. Because gradient methods cannot be used, we use the direct search complex algorithm DBCPOL in Fortran 77 to simultaneously solve for all consumption, leisure, and investment (for the OJT model) values when maximizing lifetime utility subject to the appropriate human and physical capital accumulation constraints. In the OJT model, this amounts to trying a path for investment and leisure. Calculating the optimal consumption path given this investment and leisure path is trivial. Then, total lifetime utility is found. These steps are iterated using the DBCPOL algorithm until the maximizing consumption, leisure, and investment profiles are found. We use multiple starting values for each profile to determine whether the optimization procedure produces global optima. Reasonable starting values for investment and leisure generally produce a global optimum. In particular, we use the optimal paths for leisure and investment when the EITC is not imposed as initial guesses, and we always find that this

leads to a global optimum. A similar procedure is used for the LBD model, dropping investment I. 


\section{Appendix D}

\section{Parameter Estimates}

This appendix reports the parameter estimates and goodness of fit for the models used in the paper. Tables D-1 and D-2 report the parameter estimates for the OJT and LBD models, respectively. The weighted sum of squared errors are reported in Tables D-3 and D-4, along with a decomposition of those errors into the contribution due errors in predicting hours and wages. 


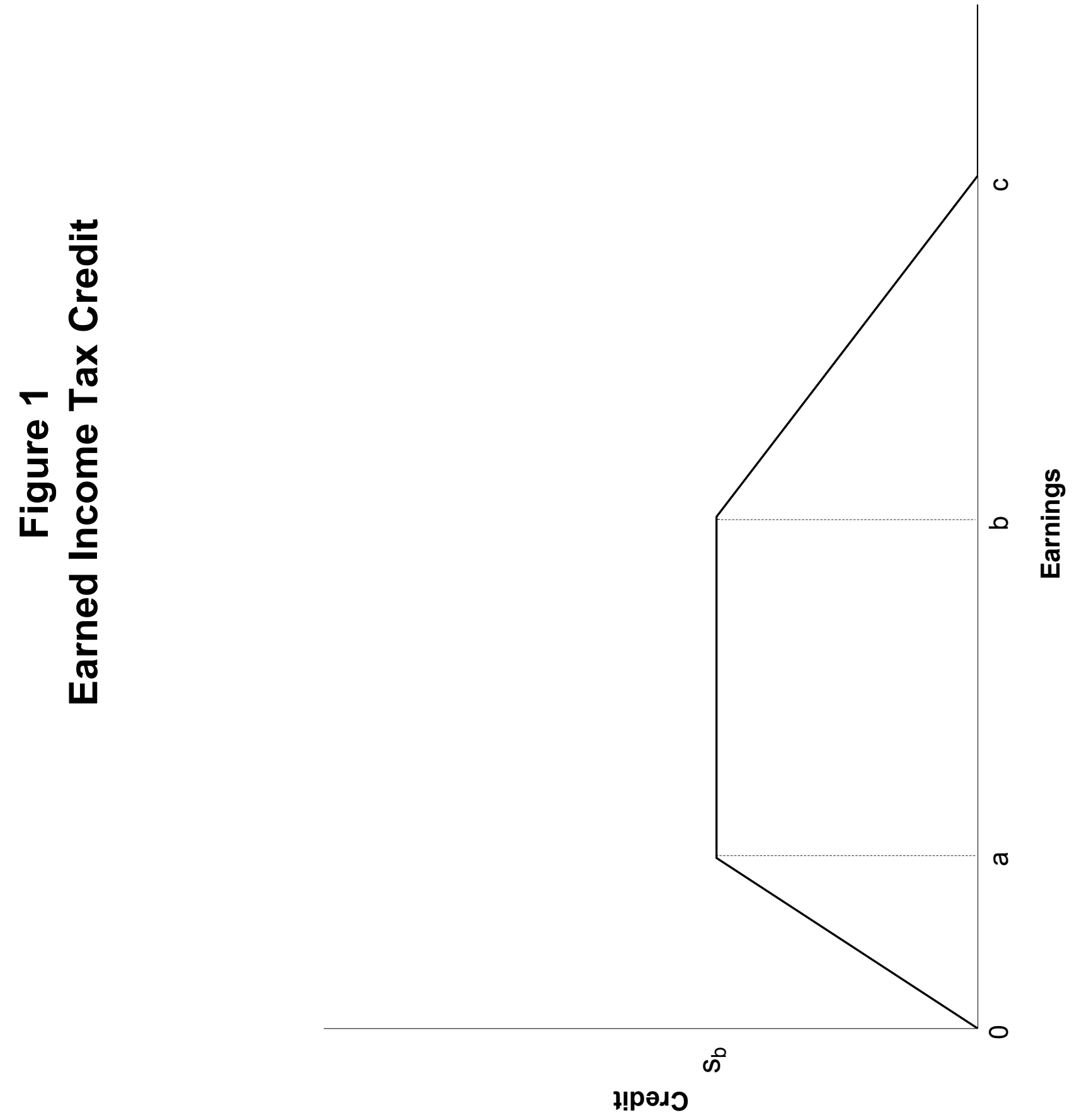




\section{Figure 2: Simulated Effects of EITC on Investment (OJT model)}
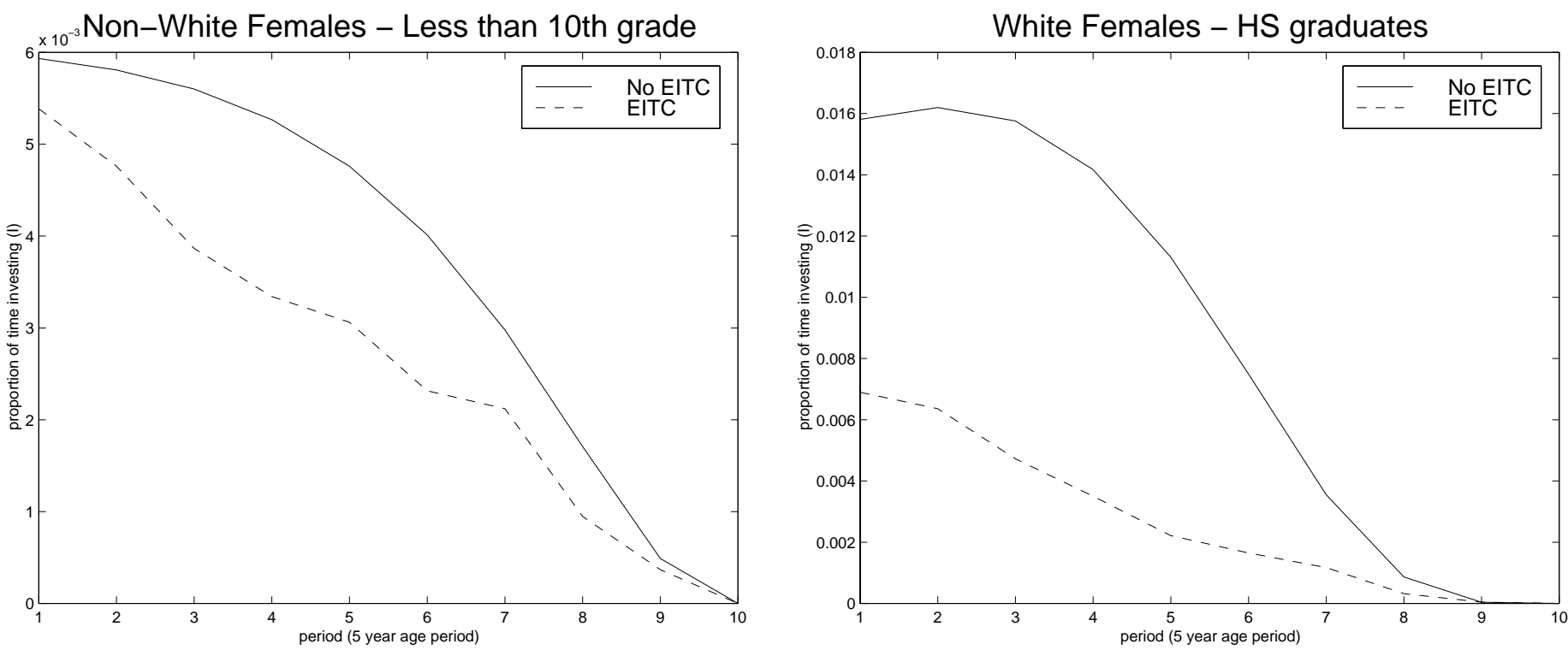

Figure 3: Simulated Effects of EITC on Hours Worked (OJT model)
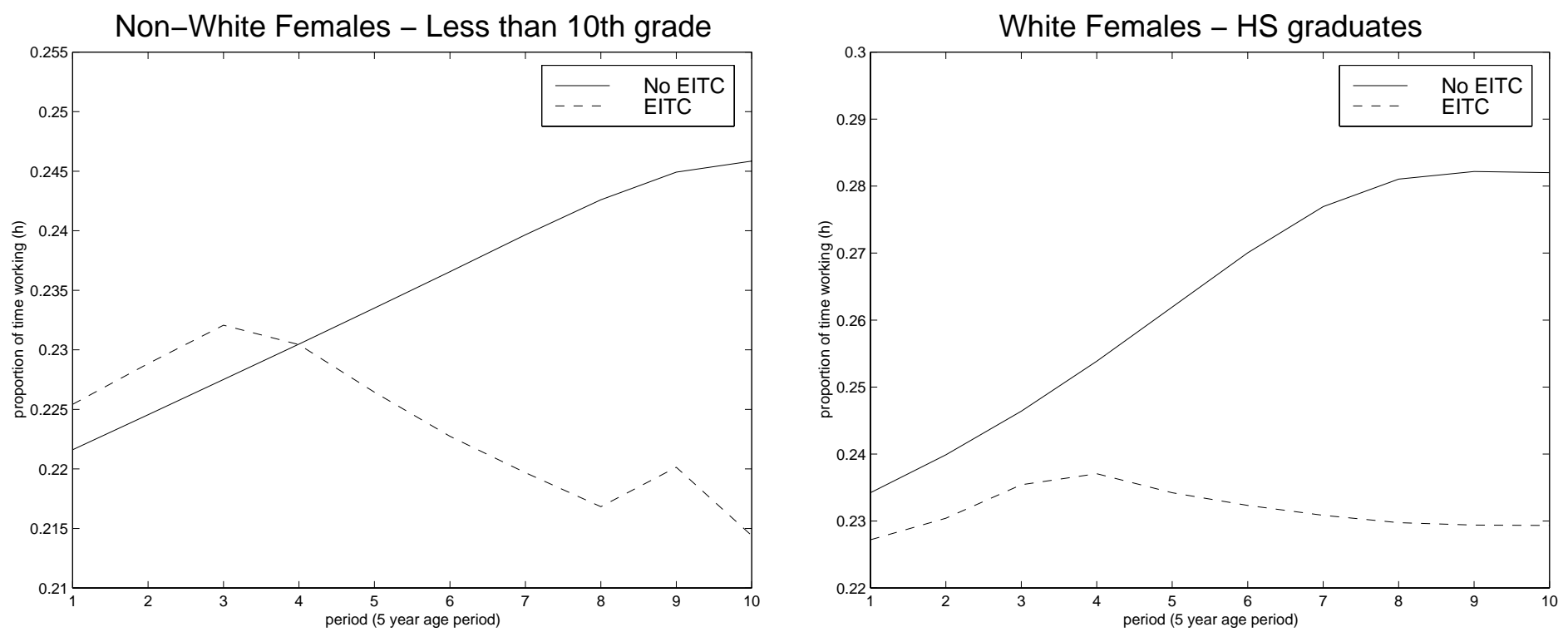


\section{Figure 4: Simulated Effects of EITC on Human Capital (OJT model)}
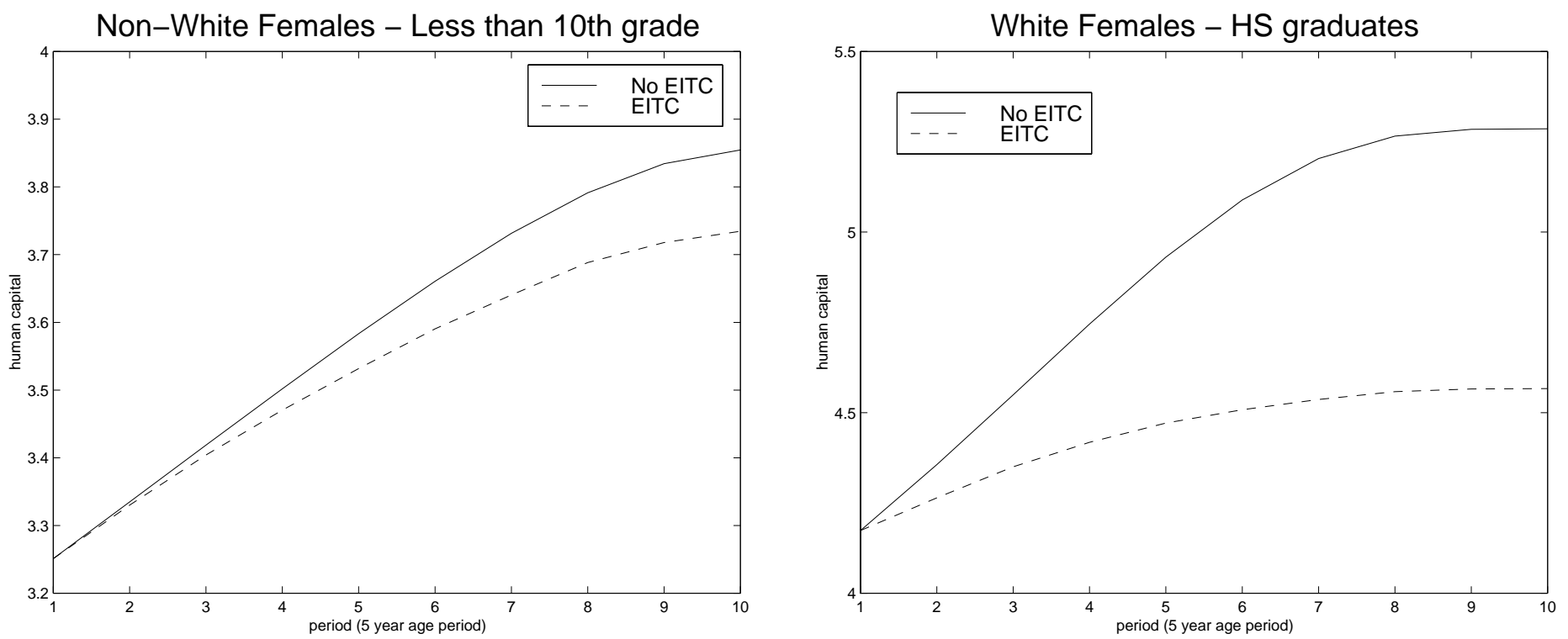

Figure 5: Simulated Effects of EITC on Wage Rates (OJT model)
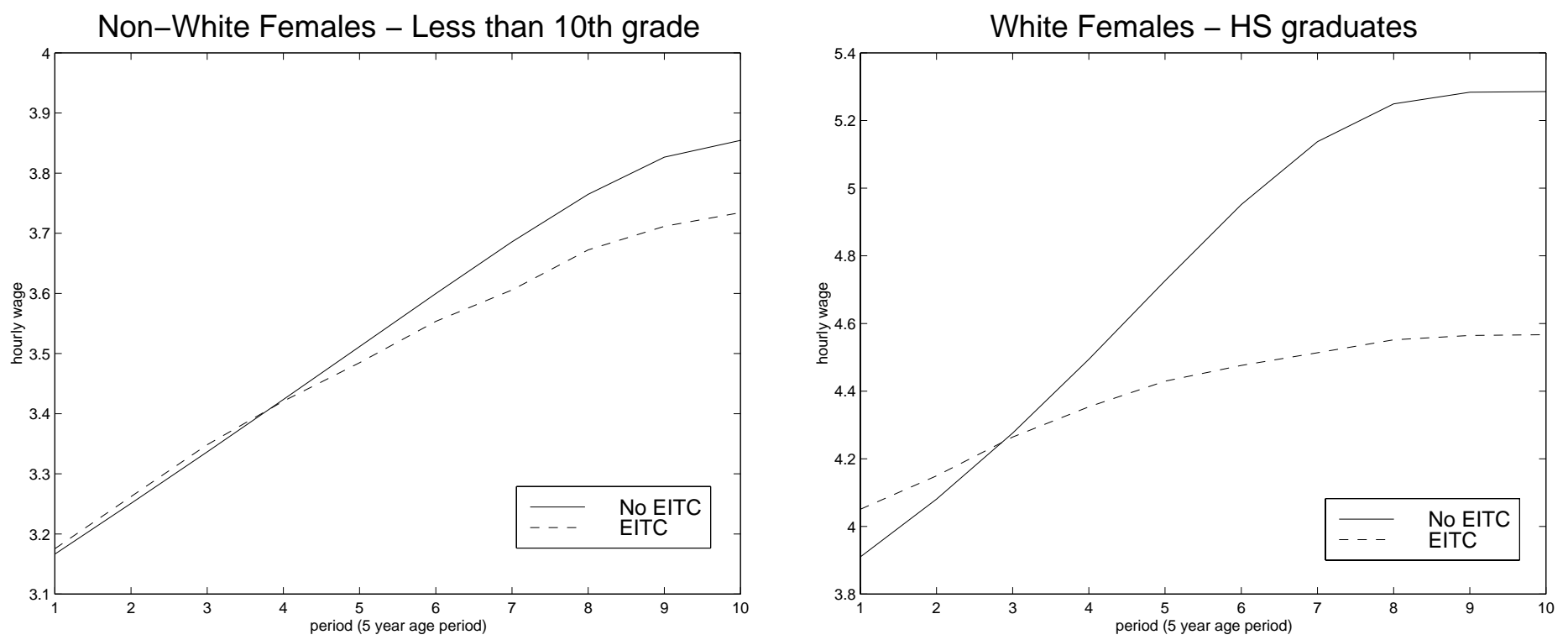


\section{Figure 6: Simulated Effects of EITC on Wage Income (OJT model)}
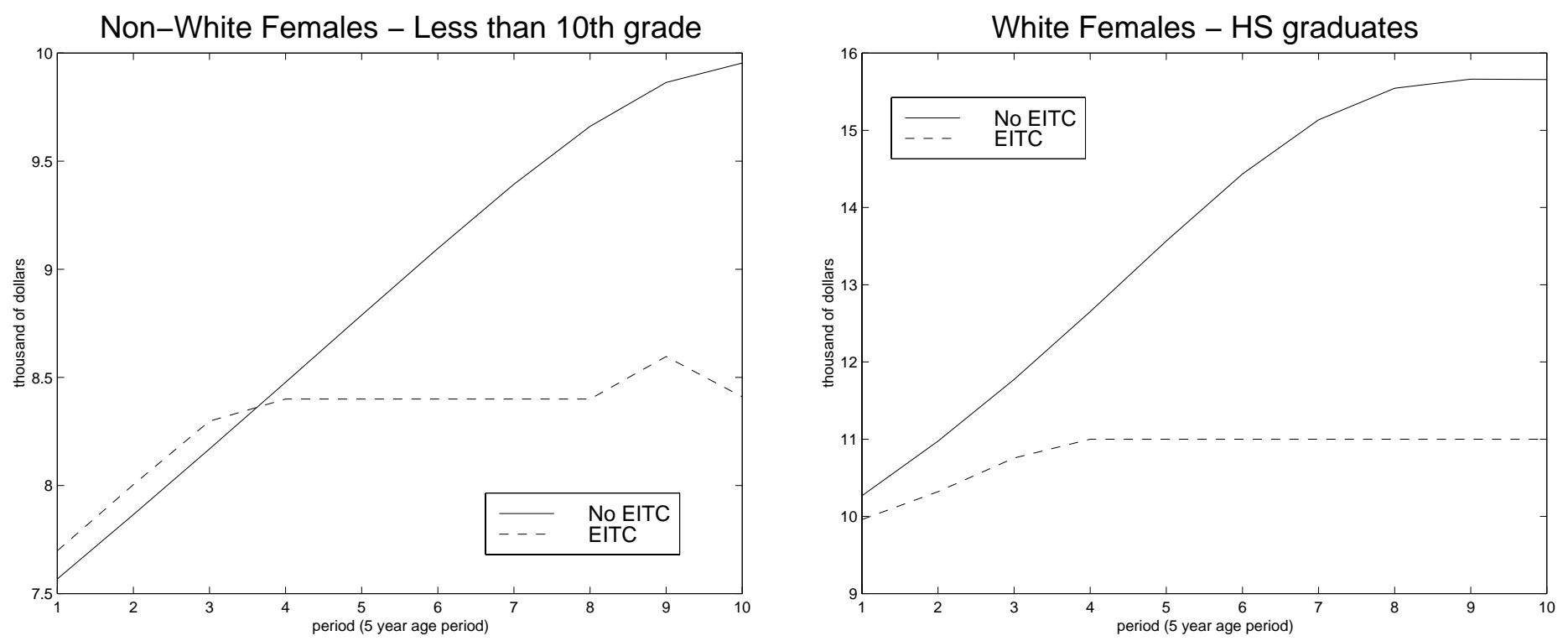

Figure 7: Simulated Effects of EITC on Hours Worked (LBD model)
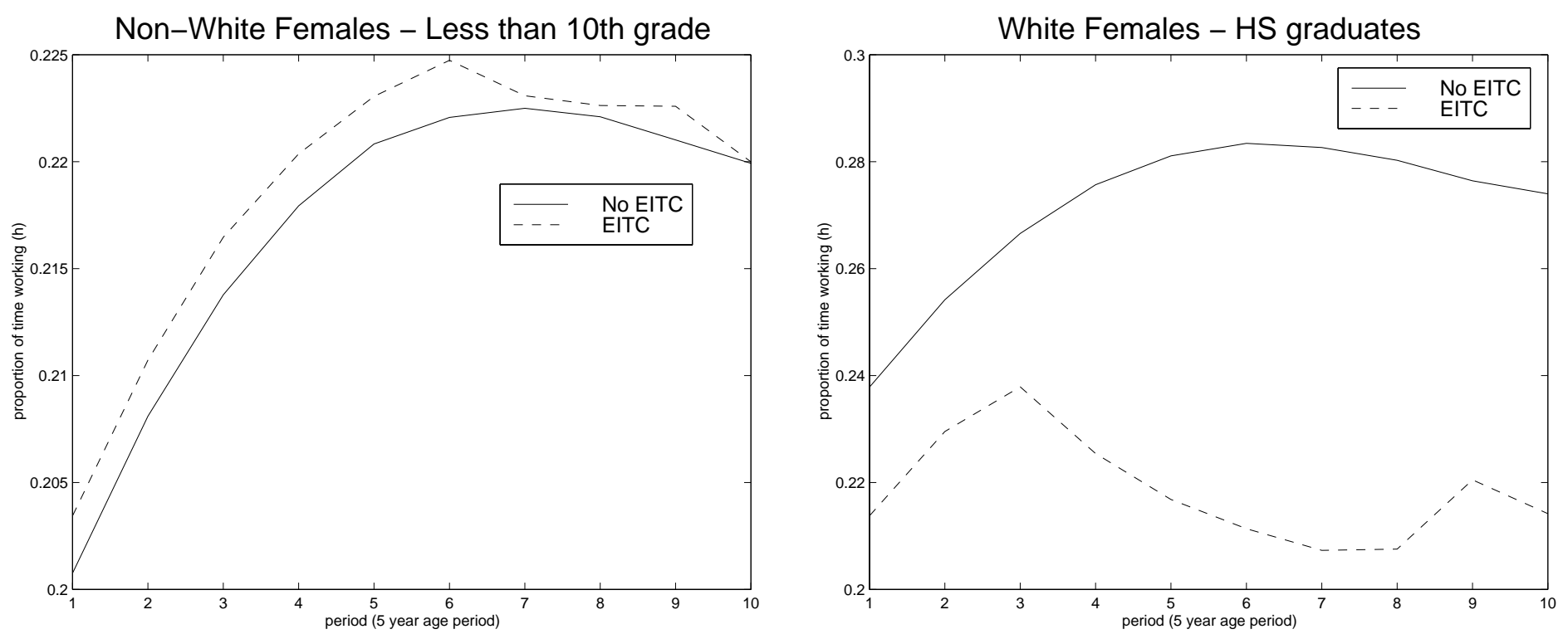


\section{Figure 8: Simulated Effects of EITC on Human Capital (LBD model)}
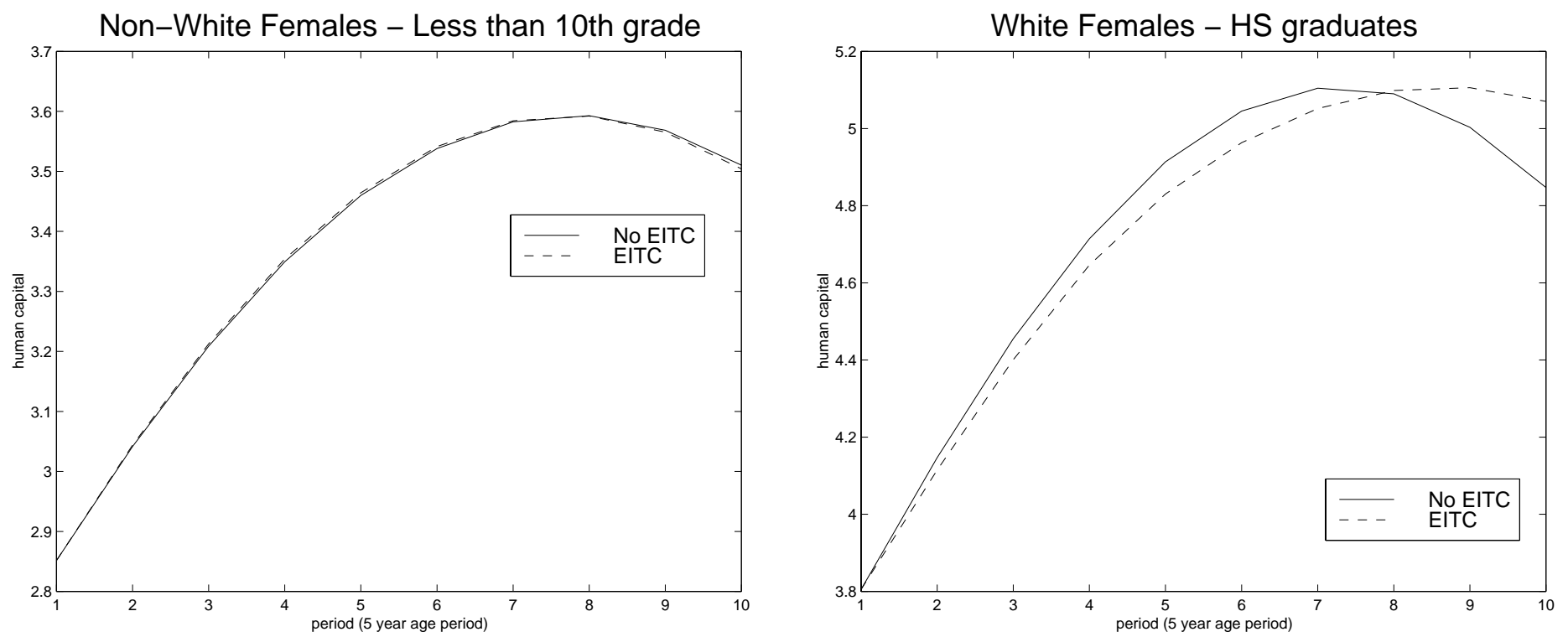

Figure 9: Changes in Hourly Wages due to Increases in Hours Worked (LBD model)
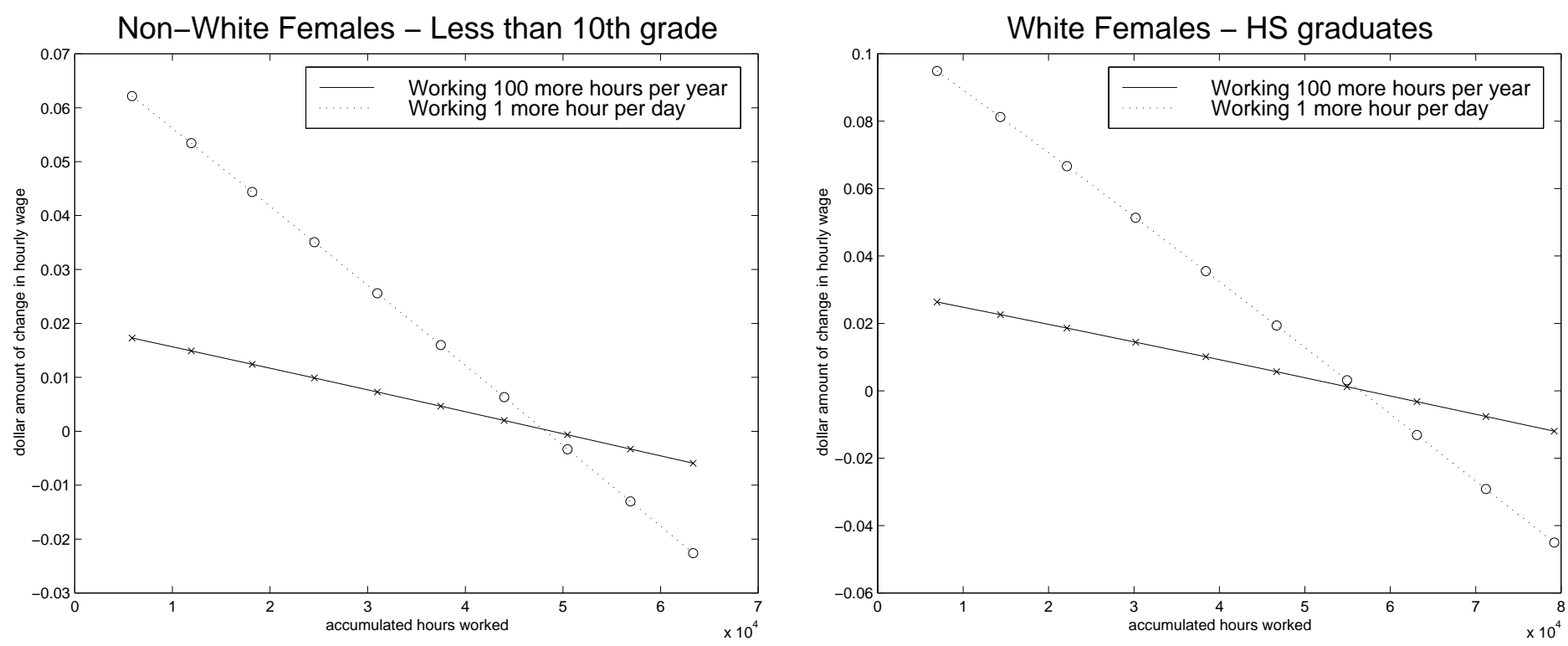


\section{Figure 10: Simulated Effects of EITC on Wage Income (LBD model)}
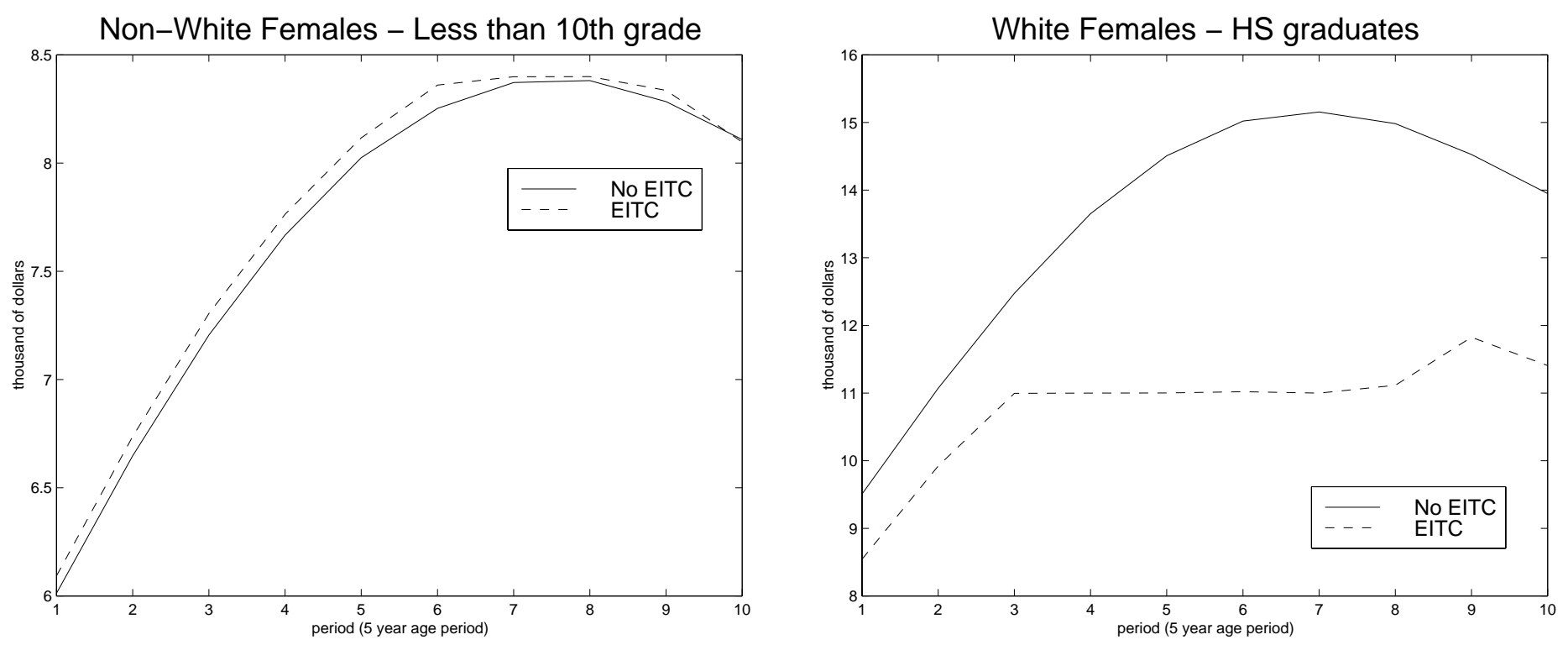
Table 1: Earned Income Tax Credit for 1994

\begin{tabular}{lccc}
\hline \hline & Families with One Child & $\begin{array}{c}\text { Families with Two } \\
\text { or More Children }\end{array}$ & Childless Adults \\
\hline Phase-in & & & \\
Income Range & $\$ 1-\$ 7,749$ & $\$ 1-\$ 8,424$ & $\$ 1-\$ 3,999$ \\
Phase-in Rate & $26.3 \%$ & & $7.64 \%$ \\
Plateau & & $\$ 8,0 \%$ & \\
Income Range & $\$ 7,750-\$ 10,999$ & $\$ 2,528$ & $\$ 10,999$ \\
Maximum Credit & $\$ 2,038$ & & $\$ 306$ \\
Phase-out & & $\$ 11,000-\$ 25,295$ & $\$ 5,000-\$ 8,999$ \\
Income Range & $\$ 11,000-\$ 23,754$ & $17.68 \%$ & $7.65 \%$ \\
Phase-out Rate & $15.98 \%$ & &
\end{tabular}


Table 2: Distribution of Households Qualifying for the EITC

\begin{tabular}{|c|c|c|c|c|c|}
\hline & \multicolumn{5}{|c|}{ Percentage by Education Level: } \\
\hline & $<10$ yrs & $11-12$ yrs & HS grad & Some College & College Grad \\
\hline \multicolumn{6}{|l|}{ No Qualifying Children } \\
\hline Single Women $(36.1 \%)$ & 9.40 & 6.98 & 33.97 & 33.16 & 16.48 \\
\hline Single Men (29.8\%) & 10.05 & 8.21 & 32.23 & 31.25 & 18.26 \\
\hline Married $(34.1 \%)$ & 18.76 & 9.11 & 37.19 & 18.33 & 16.61 \\
\hline \multicolumn{6}{|l|}{ One Qualifying Child } \\
\hline Single Women (36.4\%) & 5.74 & 8.38 & 42.09 & 36.72 & 7.06 \\
\hline Single Men $(8.2 \%)$ & 9.21 & 10.04 & 47.70 & 26.36 & 6.69 \\
\hline Married $(55.4 \%)$ & 15.21 & 10.20 & 39.95 & 22.94 & 11.69 \\
\hline \multicolumn{6}{|c|}{ Two or More Qualifying Children } \\
\hline Single Women $(23.3 \%)$ & 8.06 & 11.65 & 38.25 & 33.69 & 8.35 \\
\hline Single Men $(3.5 \%)$ & 11.54 & 12.82 & 42.31 & 25.00 & 8.33 \\
\hline Married $(73.1 \%)$ & 17.79 & 9.14 & 38.02 & 23.77 & 11.28 \\
\hline
\end{tabular}


Table 3: Distribution of Earnings for Working Female High

School Dropouts Over the EITC Schedule

(Household Heads with Children)

\begin{tabular}{|c|c|c|c|c|c|c|c|c|}
\hline \multirow{2}{*}{ 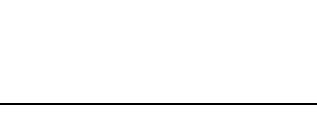 } & \multicolumn{7}{|c|}{ Percentage in EITC Region: } & \multirow[t]{2}{*}{ No. of Obs. } \\
\hline & $\mathrm{I}$ & II & III & IV & $\mathrm{V}$ & VI & VII & \\
\hline \multicolumn{9}{|l|}{ One Child } \\
\hline All & 35.5 & 4.3 & 8.7 & 4.0 & 31.1 & 2.0 & 14.4 & 299 \\
\hline Age $<30$ & 50.00 & 2.56 & 7.69 & 1.28 & 21.79 & 0.00 & 16.67 & 78 \\
\hline Ages $30-40$ & 39.13 & 2.90 & 7.25 & 5.80 & 31.88 & 4.35 & 8.70 & 69 \\
\hline Ages $40-50$ & 29.67 & 4.40 & 10.99 & 3.30 & 34.07 & 2.20 & 15.38 & 91 \\
\hline Age $>50$ & 21.31 & 8.20 & 8.20 & 6.56 & 37.70 & 1.64 & 16.39 & 61 \\
\hline Single Women & 42.50 & 5.63 & 8.13 & 5.63 & 31.25 & 0.63 & 6.25 & 160 \\
\hline Married Women & 27.34 & 2.88 & 9.35 & 2.16 & 30.94 & 3.60 & 23.74 & 139 \\
\hline \multicolumn{9}{|l|}{ Two Children } \\
\hline All & 42.7 & 1.2 & 10.9 & 3.9 & 27.6 & 2.8 & 10.9 & 431 \\
\hline Age $<30$ & 47.50 & 0.83 & 9.17 & 5.00 & 22.50 & 1.67 & 13.33 & 120 \\
\hline Ages $30-40$ & 39.59 & 1.52 & 11.17 & 1.52 & 31.98 & 4.57 & 9.64 & 197 \\
\hline Ages $40-50$ & 41.77 & 0.00 & 13.92 & 7.59 & 22.78 & 1.27 & 12.66 & 79 \\
\hline Age $>50$ & 45.71 & 2.86 & 8.57 & 5.71 & 31.43 & 0.00 & 5.71 & 35 \\
\hline Single Women & 56.94 & 1.44 & 11.96 & 2.39 & 23.44 & 0.96 & 2.87 & 209 \\
\hline Married Women & 29.28 & 0.90 & 9.91 & 5.41 & 31.53 & 4.50 & 18.47 & 222 \\
\hline
\end{tabular}

Note: EITC regions correspond to: (I) phase-in region, (II) kink between the phase-in and plateau region, (III) plateau region, (IV) kink between plateau and phase-out region, (V) phase-out region, (VI) maximum allowable earnings, and (VII) above the maximum allowable earnings limit. See Appendix A for a precise definition of these regions. 
Table 4: Distribution of Earnings for Working Female High

School Graduates Over the EITC Schedule

(Household Heads With Children)

\begin{tabular}{|c|c|c|c|c|c|c|c|c|}
\hline & \multicolumn{7}{|c|}{ Percentage in EITC Region: } & \multirow[t]{2}{*}{ No. of Obs. } \\
\hline & $\mathrm{I}$ & II & III & IV & $\mathrm{V}$ & VI & VII & \\
\hline \multicolumn{9}{|l|}{ One Child } \\
\hline All & 21.4 & 1.9 & 6.9 & 2.1 & 31.6 & 3.9 & 32.1 & 893 \\
\hline Age $<30$ & 32.02 & 2.19 & 9.65 & 3.51 & 32.02 & 3.51 & 17.11 & 228 \\
\hline Ages $30-40$ & 20.07 & 2.08 & 6.92 & 1.73 & 31.83 & 3.81 & 33.56 & 289 \\
\hline Ages $40-50$ & 16.67 & 1.19 & 5.16 & 1.59 & 30.56 & 3.57 & 41.27 & 252 \\
\hline Age $>50$ & 14.52 & 2.42 & 5.65 & 1.61 & 32.26 & 5.65 & 37.90 & 124 \\
\hline Single Women & 25.64 & 2.91 & 8.55 & 2.55 & 37.45 & 4.18 & 18.73 & 550 \\
\hline Married Women & 14.58 & 0.29 & 4.37 & 1.46 & 22.16 & 3.50 & 53.64 & 343 \\
\hline \multicolumn{9}{|l|}{ Two Children } \\
\hline All & 27.0 & 1.2 & 6.3 & 3.2 & 28.8 & 4.0 & 29.4 & 966 \\
\hline Age $<30$ & 40.85 & 0.47 & 7.51 & 4.69 & 29.58 & 0.94 & 15.96 & 213 \\
\hline Ages $30-40$ & 25.56 & 2.03 & 6.29 & 2.84 & 29.21 & 4.87 & 29.21 & 493 \\
\hline Ages $40-50$ & 17.14 & 0.48 & 3.81 & 2.86 & 29.52 & 4.29 & 41.90 & 210 \\
\hline Age $>50$ & 24.00 & 0.00 & 12.00 & 2.00 & 18.00 & 8.00 & 36.00 & 50 \\
\hline Single Women & 37.47 & 1.55 & 7.32 & 3.33 & 34.37 & 3.33 & 12.64 & 451 \\
\hline Married Women & 17.86 & 0.97 & 5.44 & 3.11 & 23.88 & 4.66 & 44.08 & 515 \\
\hline
\end{tabular}

Note: EITC regions correspond to: (I) phase-in region, (II) kink between the phase-in and plateau region, (III) plateau region, (IV) kink between plateau and phase-out region, (V) phase-out region, (VI) maximum allowable earnings, and (VII) above the maximum allowable earnings limit. See Appendix A for a precise definition of these regions. 
Table 5: Estimated Life-Cycle Progression Through the EITC Schedule (OJT Simulations Based on 1994 EITC Schedule for Two Children)

\begin{tabular}{lcc}
\hline \hline & $\begin{array}{c}\text { Initial } \\
\text { EITC Region }\end{array}$ & $\begin{array}{c}\text { Final } \\
\text { EITC Region }\end{array}$ \\
& & \\
Whites & & plateau \\
$<10$ Years of School & phase-in/plateau kink & phase-out \\
$10-11$ Years of School & phase-in & plateau/phase-out kink \\
12 Years of School & plateau & \\
& & phase-in/plateau kink \\
Non-Whites & & plateau \\
$<10$ Years of School & phase-in & phase-out \\
$10-11$ Years of School & phase-in & \\
12 Years of School & plateau & \\
& & \\
\hline
\end{tabular}


Table 6: Effects of EITC (OJT Model)

\begin{tabular}{lccc}
\hline \hline & $\begin{array}{c}\text { \% Change in } \\
\text { PV of Earnings }\end{array}$ & $\begin{array}{c}\text { Change in } \\
\text { of Earnings } \\
\text { (thousands of dollars) }\end{array}$ & $\begin{array}{c}\text { PV of received } \\
\text { subsidies }\end{array}$ \\
\hline Whites & & & \\
$<10$ Years of School & -6.32 & -4.68 & 20.61 \\
10-11 Years of School & -1.97 & -1.29 & 18.91 \\
12 Years of School & -9.25 & -8.65 & 20.61 \\
& & & \\
Non-Whites & & & 19.69 \\
$<10$ Years of School & -0.13 & -0.09 & 18.26 \\
10-11 Years of School & -0.79 & -0.49 & 20.30 \\
12 Years of School & -8.68 & -8.29 & \\
& & & \\
\hline
\end{tabular}


Table 7: Annual Compensation (in thousand of dollars) Necessary to Make People Indifferent between Employment and Unemployment (OJT Simulations Based on 1994 EITC Schedule for Two Children)

\begin{tabular}{lcc}
\hline \hline & without EITC & with EITC \\
\hline Whites & & \\
$<10$ Years of School & 5.40 & 5.39 \\
$10-11$ Years of School & 4.84 & 4.79 \\
12 Years of School & 6.70 & 6.69 \\
& & \\
Non-Whites & & 4.95 \\
$<10$ Years of School & 4.95 & 4.47 \\
$10-11$ Years of School & 4.49 & 7.48 \\
12 Years of School & 7.52 & \\
& & \\
\hline
\end{tabular}


Table 8: Employment Rates and Average Human Capital Levels (OJT Simulations Based on 1994 EITC Schedule for Two Children)

\begin{tabular}{lcccc}
\hline \hline & $\begin{array}{c}\text { \% of } \\
\text { Population }\end{array}$ & $\begin{array}{c}\text { Employment } \\
\text { Rate }\end{array}$ & $\begin{array}{c}\text { Average } \\
\text { Human Capital }\end{array}$ & $\begin{array}{c}\text { Average } \\
\text { Supplied HC }\end{array}$ \\
\hline Whites & & & & \\
$\quad<10$ Years of School & 3.27 & 41.88 & 1.59 & 0.40 \\
10-11 Years of School & 2.80 & 54.80 & 2.32 & 0.55 \\
12 Years of School & 15.86 & 72.83 & 3.56 & 0.94 \\
& & & & \\
Non-Whites & & & & 0.32 \\
$<$ 10 Years of School & 0.74 & 37.61 & 1.35 & 0.41 \\
10-11 Years of School & 0.87 & 45.83 & 1.71 & 0.96 \\
12 Years of School & 3.01 & 68.19 & 3.42 & \\
\hline
\end{tabular}

Note: Human capital averages (both potential and supplied) are lifetime averages of levels obtained in the simulations for each group, assuming an equal distribution of workers across all age groups. They are inclusive of non-workers who we assume have potential skill levels equal to $H_{0}$ and supply zero skills to the market. 
Table 9: Effects of EITC on Potential Skill Levels (OJT Simulations Based on 1994 EITC Schedule for Two Children)

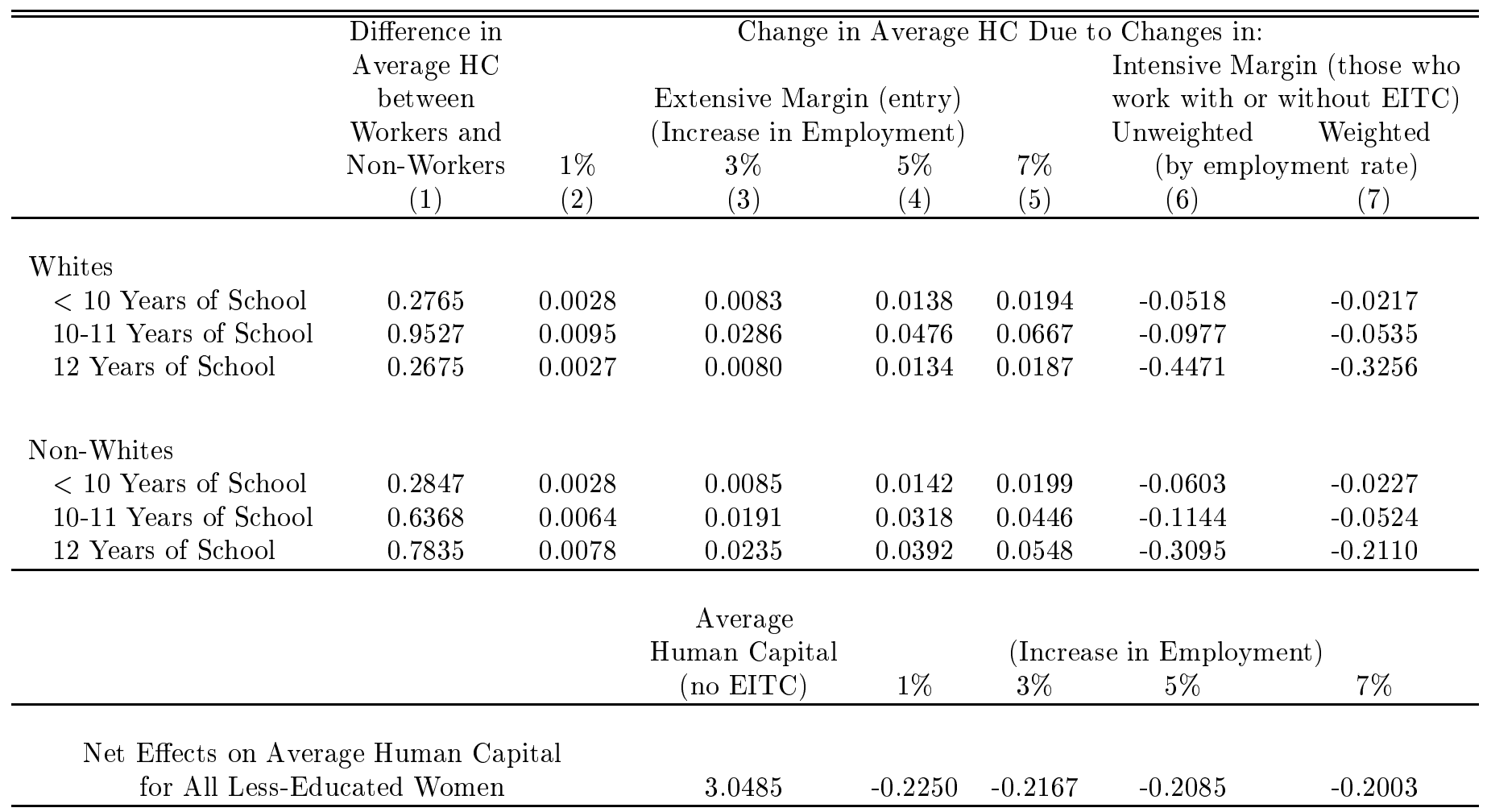

Note: Human capital averages are lifetime averages of levels obtained in the simulations for each group, assuming an equal distribution of workers across all age groups. They are inclusive of non-workers who we assume have potential skill levels equal to $H_{0}$.

The values assumed for increase in employment denote percentage points of increase. 
Table 10: Effects of EITC on Skills Supplied to the Market (OJT Simulations Based on 1994 EITC Schedule for Two Children)

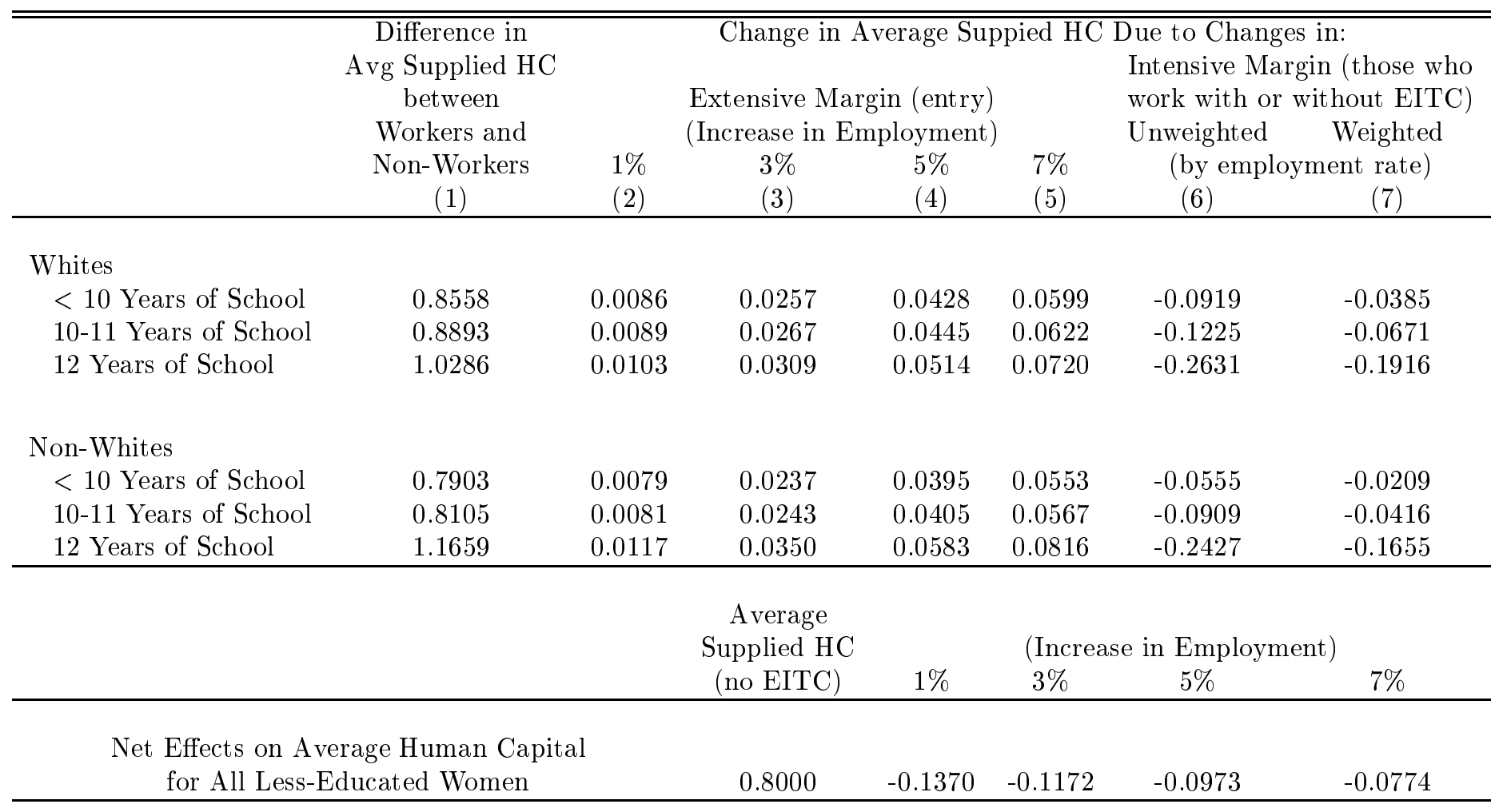

Note: Supplied human capital averages are lifetime averages of levels obtained in the simulations for each group, assuming an equal distribution of workers across all age groups. They are inclusive of non-workers who we assume have potential skill levels equal to $H_{0}$ and supply zero skills to the market.

The values assumed for increase in employment denote percentage points of increase. 
Table 11: Estimated Life-Cycle Progression Through the EITC Schedule (LBD Simulations Based on 1994 EITC Schedule for Two Children)

\begin{tabular}{|c|c|c|}
\hline & $\begin{array}{c}\text { Initial } \\
\text { EITC Region }\end{array}$ & $\begin{array}{c}\text { Final } \\
\text { EITC Region }\end{array}$ \\
\hline $\begin{array}{l}\text { Whites } \\
<10 \text { Years of School } \\
10-11 \text { Years of School } \\
12 \text { Years of School }\end{array}$ & $\begin{array}{c}\text { phase-in } \\
\text { phase-in/plateau kink } \\
\text { plateau }\end{array}$ & $\begin{array}{l}\text { plateau } \\
\text { phase-out } \\
\text { phase-out }\end{array}$ \\
\hline $\begin{array}{l}\text { Non-Whites } \\
<10 \text { Years of School } \\
10-11 \text { Years of School } \\
12 \text { Years of School }\end{array}$ & $\begin{array}{c}\text { phase-in } \\
\text { phase-in/plateau kink } \\
\text { phase-in plateau kink }\end{array}$ & $\begin{array}{c}\text { phase-in } \\
\text { plateau } \\
\text { plateau/phase-out kink }\end{array}$ \\
\hline
\end{tabular}


Table 12: Effects of EITC when Imposed (LBD Model)

\begin{tabular}{lccc}
\hline \hline & $\begin{array}{c}\text { \% Change in } \\
\text { PV of Earnings }\end{array}$ & $\begin{array}{c}\text { Change in } \\
\text { of Earnings } \\
\text { (thousands of dollars) }\end{array}$ & $\begin{array}{c}\text { PV of received } \\
\text { subsidies }\end{array}$ \\
\hline Whites & & & \\
$<10$ Years of School & -4.34 & -3.12 & 20.18 \\
10-11 Years of School & -12.71 & -10.38 & 20.59 \\
12 Years of School & -14.20 & -13.25 & 20.60 \\
& & & 16.90 \\
Non-Whites & 1.26 & 0.70 & 20.61 \\
$<10$ Years of School & -13.30 & -10.91 & 20.58 \\
$10-11$ Years of School & -15.26 & -13.87 & \\
12 Years of School & & & \\
& & &
\end{tabular}


Table 13: Annual Compensation (in thousand of dollars) Necessary to Make People Indifferent between Employment and Unemployment (LBD Simulations Based on 1994 EITC Schedule for Two Children)

\begin{tabular}{lcc}
\hline \hline & without EITC & with EITC \\
& & \\
\hline Whites & 5.10 & 5.08 \\
$<10$ Years of School & 4.01 & 3.98 \\
10-11 Years of School & 5.39 & 5.36 \\
12 Years of School & & \\
& & \\
Non-Whites & 3.61 & 3.59 \\
$<10$ Years of School & 4.03 & 4.02 \\
10-11 Years of School & 4.50 & 4.45 \\
12 Years of School & & \\
\end{tabular}


Table 14: Employment Rates and Average Human Capital Levels (LBD Simulations Based on 1994 EITC Schedule for Two Children)

\begin{tabular}{lcccc}
\hline \hline & $\begin{array}{c}\text { \% of } \\
\text { Population }\end{array}$ & $\begin{array}{c}\text { Employment } \\
\text { Rate }\end{array}$ & $\begin{array}{c}\text { Average } \\
\text { Human Capital }\end{array}$ & $\begin{array}{c}\text { Average } \\
\text { Supplied HC }\end{array}$ \\
\hline Whites & & & & \\
< 10 Years of School & 3.27 & 41.88 & 1.54 & 0.39 \\
10-11 Years of School & 2.80 & 54.80 & 2.39 & 0.64 \\
12 Years of School & 15.86 & 72.83 & 3.43 & 0.94 \\
& & & & \\
Non-Whites & & & & 0.28 \\
< 10 Years of School & 0.74 & 37.61 & 1.27 & 0.50 \\
10-11 Years of School & 0.87 & 45.83 & 1.81 & 0.90 \\
12 Years of School & 3.01 & 68.19 & 3.16 & \\
\hline
\end{tabular}

Note: Human capital averages (both potential and supplied) are lifetime averages of levels obtained in the simulations for each group, assuming an equal distribution of workers across all age groups. They are inclusive of non-workers who we assume have potential skill levels equal to $H_{0}$ and supply zero skills to the market. 
Table 15: Effects of EITC on Potential Skill Levels (LBD Simulations Based on 1994 EITC Schedule for Two Children)

\begin{tabular}{|c|c|c|c|c|c|c|c|}
\hline & \multirow{5}{*}{$\begin{array}{c}\text { Difference in } \\
\text { Average HC } \\
\text { between } \\
\text { Workers and } \\
\text { Non-Workers } \\
(1) \\
\end{array}$} & \multirow{5}{*}{$\begin{array}{l}1 \% \\
(2) \\
\end{array}$} & \multicolumn{4}{|c|}{ "Change in Average HC Due to Changes in } & \\
\hline & & & \multirow{2}{*}{\multicolumn{2}{|c|}{$\begin{array}{l}\text { Extensive Margin (entry) } \\
\text { (Increase in Employment) }\end{array}$}} & \multirow{4}{*}{$\begin{array}{l}7 \% \\
(5) \\
\end{array}$} & \multirow{3}{*}{\multicolumn{2}{|c|}{$\begin{array}{l}\text { Intensive Margin (those who } \\
\text { work with or without EITC) } \\
\text { Unweighted Weighted } \\
\text { (by employment rate) }\end{array}$}} \\
\hline & & & & & & & \\
\hline & & & $3 \%$ & $5 \%$ & & & \\
\hline & & & $(3)$ & & & & $(7)$ \\
\hline \multicolumn{8}{|l|}{ Whites } \\
\hline$<10$ Years of School & 0.6441 & 0.0064 & 0.0193 & 0.0322 & 0.0451 & 0.0186 & 0.0078 \\
\hline 10-11 Years of School & 0.7197 & 0.0072 & 0.0216 & 0.0360 & 0.0504 & -0.0015 & -0.0008 \\
\hline 12 Years of School & 0.9035 & 0.0090 & 0.0271 & 0.0452 & 0.0632 & -0.0039 & -0.0028 \\
\hline \multicolumn{8}{|l|}{ Non-Whites } \\
\hline$<10$ Years of School & 0.5198 & 0.0052 & 0.0156 & 0.0260 & 0.0364 & 0.0011 & 0.0004 \\
\hline 10-11 Years of School & 0.5485 & 0.0055 & 0.0165 & 0.0274 & 0.0384 & 0.0219 & 0.0100 \\
\hline \multirow[t]{3}{*}{12 Years of School } & 0.9857 & 0.0099 & 0.0296 & 0.0493 & 0.0690 & 0.0194 & 0.0132 \\
\hline & & & \multirow{2}{*}{$\begin{array}{c}\text { Average } \\
\text { Human Capital } \\
\text { (no EITC) }\end{array}$} & & \multicolumn{3}{|c|}{ (Increase in Employment) } \\
\hline & & & & $1 \%$ & $3 \%$ & $5 \%$ & $7 \%$ \\
\hline $\begin{array}{l}\text { Net Effects on Aver } \\
\text { for All Less-Ed }\end{array}$ & $\begin{array}{l}\text { ge Human Cap } \\
\text { icated Women }\end{array}$ & & 2.9436 & 0.0094 & 0.0262 & 0.0430 & 0.0598 \\
\hline
\end{tabular}

Note: Human capital averages are lifetime averages of levels obtained in the simulations for each group, assuming an equal distribution of workers across all age groups. They are inclusive of non-workers who we assume have potential skill levels equal to $H_{0}$.

The values assumed for increase in employment denote percentage points of increase. 
Table 16: Effects of EITC on Skills Supplied to the Market (LBD Simulations Based on 1994 EITC Schedule for Two Children)

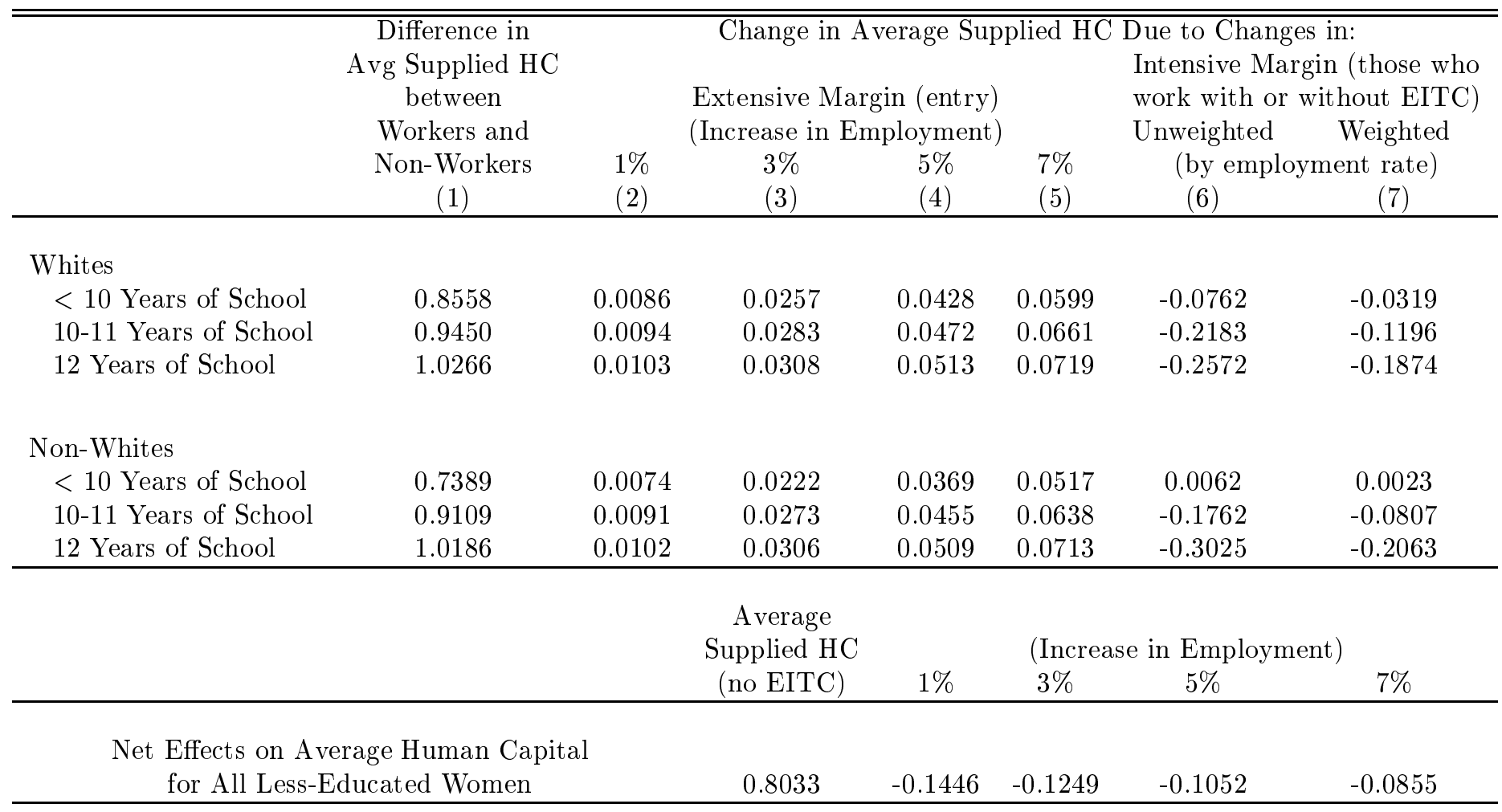

Note: Supplied human capital averages are lifetime averages of levels obtained in the simulations for each group, assuming an equal distribution of workers across all age groups. They are inclusive of non-workers who we assume have potential skill levels equal to $H_{0}$ and supply zero skills to the market.

The values assumed for increase in employment denote percentage points of increase. 
Table D-1: Parameter Values for the OJT Model

\begin{tabular}{lccccc}
\hline \hline & $\psi$ & & & & \\
& $\psi$ & & $B$ & $\alpha$ & $H_{0}$ \\
\hline Whites & & & & & \\
$\quad<10$ Years of School & 0.8901 & -5.3879 & 0.8558 & 0.6015 & 3.4585 \\
$10-11$ Years of School & 0.8971 & -6.4344 & 0.7270 & 0.3122 & 3.1871 \\
12 Years of School & 0.8947 & -5.0882 & 1.8262 & 0.8473 & 4.1736 \\
& & & & & \\
Non-Whites & & & & & \\
$\quad<10$ Years of School & 0.7751 & -6.4974 & 0.9285 & 0.6098 & 3.2512 \\
10-11 Years of School & 0.8907 & -6.0751 & 0.9656 & 0.5064 & 2.9811 \\
12 Years of School & 0.5194 & -6.3269 & 1.3129 & 0.6186 & 3.9263 \\
& & & & & \\
\hline
\end{tabular}

Table D-2: Parameter Values for the LBD Model

\begin{tabular}{lccccc}
\hline \hline & $\psi$ & $\sigma$ & $H_{0}$ & $\beta_{0}$ & $\beta_{1}$ \\
\hline & & & & & \\
Whites & & & & & \\
$\quad<10$ Years of School & 0.9555 & -5.1475 & 3.0491 & 1.2586 & -0.4397 \\
10-11 Years of School & 3.0723 & -1.3047 & 3.6451 & 1.2862 & -0.3928 \\
12 Years of School & 1.9320 & -2.5976 & 3.8051 & 1.5468 & -0.4592 \\
& & & & & \\
Non-Whites & & & & & \\
$<10$ Years of School & 1.5521 & -4.8080 & 2.8516 & 1.0161 & -0.3479 \\
10-11 Years of School & 2.8638 & -1.1183 & 3.4269 & 1.0245 & -0.3375 \\
12 Years of School & 2.8248 & -1.3371 & 3.6644 & 1.7231 & -0.5218 \\
& & & & & \\
\hline
\end{tabular}


Table D-3: Goodness of Fit (OJT Model) Weighted Sum of Squared Differences

\begin{tabular}{lccc}
\hline \hline & & & \\
& Wages & Hours & Total \\
\hline Whites & & & \\
$\quad<10$ Years of School & 16.34 & 74.86 & 91.20 \\
10-11 Years of School & 63.97 & 201.01 & 264.98 \\
12 Years of School & 150.16 & 134.43 & 284.59 \\
& & & \\
Non-Whites & & & \\
$<$ 10 Years of School & 8.92 & 24.92 & 33.84 \\
10-11 Years of School & 46.11 & 93.95 & 140.06 \\
12 Years of School & 49.00 & 96.13 & 145.13 \\
& & & \\
\hline
\end{tabular}

Table D-4: Goodness of Fit (LBD Model) Weighted Sum of Squared Differences

\begin{tabular}{lccc}
\hline \hline & & & \\
& & & \\
\hline & & & \\
Whites & & & \\
$<10$ Years of School & 18.04 & 78.06 & 96.10 \\
10-11 Years of School & 118.15 & 178.90 & 297.05 \\
12 Years of School & 52.91 & 91.14 & 144.05 \\
& & & \\
Non-Whites & & & \\
$<10$ Years of School & 12.13 & 36.98 & 49.11 \\
10-11 Years of School & 64.02 & 114.98 & 179.00 \\
12 Years of School & 19.66 & 19.93 & 39.59 \\
& & & \\
\hline
\end{tabular}

